NBER WORKING PAPER SERIES

\title{
ANALYZING THE RELATION OF UNEMPLOYMENT INSURANCE TO UNEMPLOYMENT
}

Alan L. Gustman

Working Paper No. $\underline{512}$

\section{NATIONAL BUREAU OF ECONOMIC RESEARCH 1050 Massachusetts Avenue Cambridge MA 02138}

July 1980

The research reported herein is part of the NBER's research program in Labor Studies and was supported by the Office of the Assistant Secretary for Policy, Evaluation and Research, U.S. Department of Labor, under purchase order No. B-9-M-9-4787. Any opinions expressed are those of the author and not those of the National Bureau of Economic Research. Since contractors conducting research and development projects under government sponsorship are encouraged to express their own judgment freely, this paper does not necessarily represent the official opinion or policy of the Department of Labor.

Ronald Ehrenberg, Gary Fields, Daniel Hamermesh, Joseph Hight, Robert Hutchens, my colleagues at Dartmouth, Colin Campbell, Meir Kohn, Robert Plotnick, Martin Segal, and Thomas Steinmeier and participants in a seminar presented at Columbia University all provided helpful comments. I am responsible for all remaining errors. 


\section{Analyzing the Relation of Unemployment Insurance to Unemployment}

\section{Abstract}

This paper presents a framework for analyzing the relation of unemployment insurance to unemployment and applies the framework to evaluate recent developments in the UI literature and future research needs. Unemployment is decomposed into more basic elements related to the labor market flows which determine unemployment incidence and duration. It is also disaggregated by reason for unemployment -e.g., entry into the labor force or quit last job. A matrix containing those definitional elements of unemployment which are potentially affected by the UI system forms the basis for organizing the discussion. Each component of unemployment which may be affected by variations in characteristics of the UI system is considered in turn. The discussion of each of these elements focuses on recent theoretical and empirical studies which analyze how they are influenced by features of the UI system. By proceeding systematically through the elements which comprise unemployment and considering the major behavioral explanations linking the unemployment insurance system to unemployment, it is possible to determine where the analysis has proceeded satisfactorily and where major gaps remain.

Alan L. Gustman Department of Economics Dartmouth College Hanover, New Hampshire 03755 
The literature exploring the effects of unemployment insurance (UI) on unemployment has grown rapidly in recent years. The scope of its coverage has widened and the sophistication of analyses has increased. Such diverse topics as the effects of parameters of the payroll tax schedule on labor force turover (Frank Brechling, 1979), the implications of the benefit schedule for labor force participation (Daniel S. Hamermesh, 1979a), the impact of limitations on the duration of UI benefits for the duration of unemployment (Robert Moffit and Walter Nicholson, 1979), and the effects of UI eligibility rules on quit unemployment (Stephen T. Marston, 1979), were covered in papers from 1979 alone. This literature has been surveyed thoroughly and insightfully by Gary Fields (1977) Daniel Hamermesh (1977) (1978b), Finis Welch (1977) and Robert Topel and Finis Welch (1979).

Despite this recent progress, those designing policy and planning the research agenda within the Labor Department and other interested researchers do not have available a clear framework to guide them in fitting together the results of these diverse studies, and to help them determine in a systematic way what information is required if a complete picture of the relation of unemployment insurance to unemployment is to emerge. The purpose of this paper is to fill that gap by presenting a framework for analysis, illustrating its relation to recent developments in the literature and applying it to provide an indication of research needs. 1

${ }^{1}$ Although a large number of articles are discussed, this paper is not meant to provide a complete survey of the literature. An effort has been made, however, to include the most important of the recent contributions. 
In focusing on the relation of the UI system to unemployment, and in further restricting the discussion to implications of UI on the microeconomic level, a number of potentially important benefits of the UI system are not discussed. Subjects which are not analyzed here include:

a) the role of UI as an automatic stabalizer (see Hamermesh, 1977, and George M. Von Furstenberg, 1976);

b) the impact of UI on consumption patterns (see Hamermesh, 1979b);

c) the value of any redistribution of income which is brought about by the UI system (see, however, Martin S. Feldstein, 1974, and Ronald G. Ehrenberg, Robert Hutchens and Robert Smith, 1978 and Hamermesh, 1977, 1980);

d) UI's impact on the quality of job matches (except as improved

matches affect later unemployment);

e) the value of reduced uncertainty created by the availability of

insurance and any resulting changes in behavior, such as increased occupational specialization. (See tihe discussion of UI as insurance in Topel and Welch, 1979). ${ }^{1}$

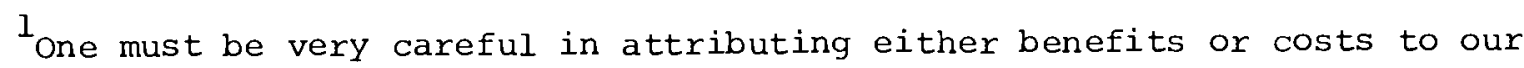
public UI system to recognize that in the absence of a federal program, the demand for insurance would have led to the emergence of private programs, at least in the case of larger firms which could take advantage of economies of scale. Indeed, there were some union-based UI programs in existence before the law establishing the UI system was passed. If the development of unemployment insurance as a fringe benefit followed the course taken by pension programs during the post-war period, for example, private UI would have become available in union markets and perhaps also in the nonunion sector. Thus, while the provision through the public sector of unemployment insurance to workers may affect the likelihood of unemployment in comparison with a counter-factual situation where no UI program is available, in evaluating the effects of a public UI program, it would seem most appropriate to assume that in the absence of a public program private insurance would have been available to many covered workers. To the extent that such problems as moral hazard would have to be faced by privately run UI programs, the public system of unemployment insurance is not completely responsible for desirable or adverse impacts associated with the existence of unemployment insurance, per se. 
Since the discussion does not focus on some of the important, intended effects of the UI system, it would be inappropriate to derive from it any broad conclusions about the relative costs and benefits of the UI system. In principle, the study of how a public policy affects some economic outcome should be relatively straightforward. First a model explaining how the dependent variable--the economic outcome--is determined in the absence of the program would either be developed for the problem at hand, or if already available, simply be applied. Second, the public policy would be introduced into the model as a constraint. The new outcome would be seen to be determined by the parameters of the public policy program and the basic relationships which determined the outcome in the absence of the program. To test the effects of the policy on the outcome, major determinants of the dependent variable exclusive of the policy would be standardized for, appropriate econometric adjustments made if required, and the effects of policy parameters on the outcome measured.

There is, however, an important complication which, although not unique to the analysis of the UI system, is more pronounced for studies of the relation of UI to unemployment than it is for analyses of many other public policies in the labor market. Specifically, neither the dependent variable nor the policy has only a single dimension. Nor is there only a single behavioral relation linking the policy to the outcome. In the case of the dependent variable, there are different subgroups of the unemployed--job leavers, those on temporary or permanent layoff, other job losers, entrants. Moreover, as the literature on unemployment has taught us, unemployment is 
a dynamic, not a static phenomenon. ${ }^{1}$ The unemployed is an everchanging group of individuals, some just entering the pool of unemployed, others leaving. The various labor market flows which determine an individual's unemployment experience are reflected in such measures as the probability of losing the last job through an indefinite layoff, the probability of becoming unemployed after such a job loss, and eventually the probability of exiting unemployment, either as a result of securing a new job or of leaving the labor force.

The UI system includes sets of rules and schedules which are characterized by complex relations among earnings, benefits, taxes, and unemployment experience. The large set of behavioral considerations linking the various flows comprising unemployment with the UI system reflects the existence of many kinds of decisions required of both demanders and suppliers of labor in the alternative circumstances which they face. Thus instead of a simple dependent and independent variable, we have a large set of possible outcomes and a complex set of policy parameters.

The first part of this paper develops the framework for viewing studies of the relation of the UI system to unemployment. The framework is then used as an outline for a discussion of the theoretical and empirical developments in the literature. A final section takes note of the questions for future research that emerge from the discussion.

$l_{\text {For recent discussions of unemployment and the labor market flows }}$ which determine it, see papers by Feldstein, (1973), George Perry, (1972), Stephen T. Marston, (1976), Kim B. Clark and Lawrence H. Summers, (1979), and Ronald G. Ehrenberg, (1979). 


\section{Analytical Framework}

This section sets out the analytical framework. Three steps are involved. First, the number unemployed, the dependent variable, is decomposed into more basic elements. Second, the dimensions of UI policy are specified. Third, the theories linking the UI system to the elements comprising unemployment are explored.

A. Decomposing Unemployment

Reasons for Becoming Unemployed

To begin, classify the unemployed according to the previous state they were in before becoming unemployed, and according to the nature of the separation from that previous state. The number who are newly unemployed in the current period may be viewed as falling into five groups. ${ }^{1}$

$$
\mu=\sum_{i=1}^{5} \mu_{i}
$$

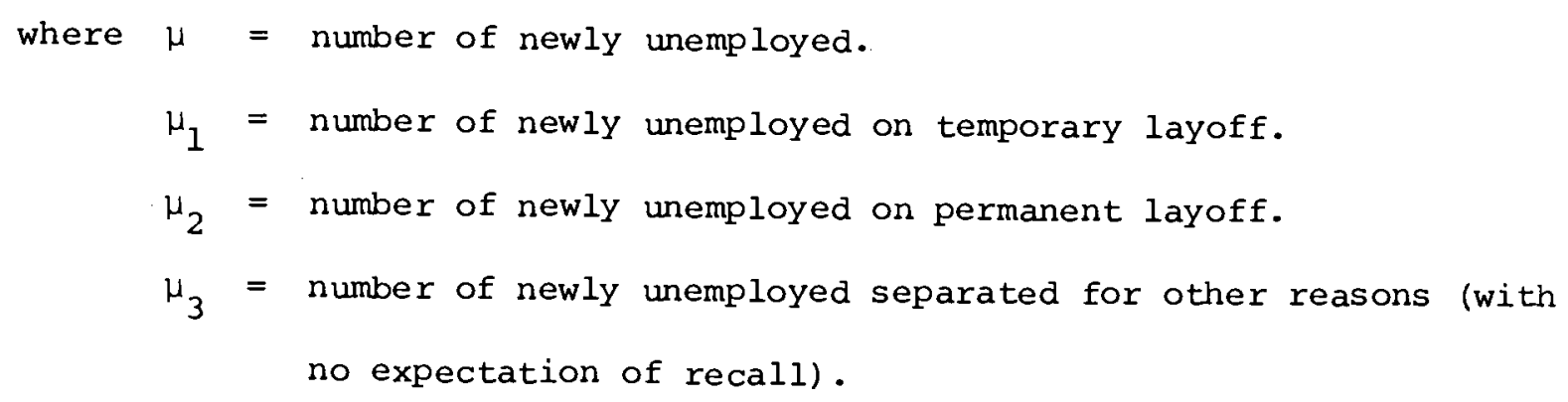

$1_{A}$ study by. Linda Leighton and Jacob Mincer (1979) analyzing the reasons for youth unemployment provided the basis for the procedure followed here in disaggregating unemployment by category and into more basic flows. Martin $\mathrm{s}$. Feldstein (1975) and Robert E. Hall (1978) discuss disaggregating the unemployed into the groups such as those specified in Equation 1 . In this framework, new entrants and reentrants have been combined in a single category. It should be noted, however, that some reentrants may be eligible for UI benefits, while new entrants are not. Therefore, it may at times be important to distinguish among these two types of entrants. 


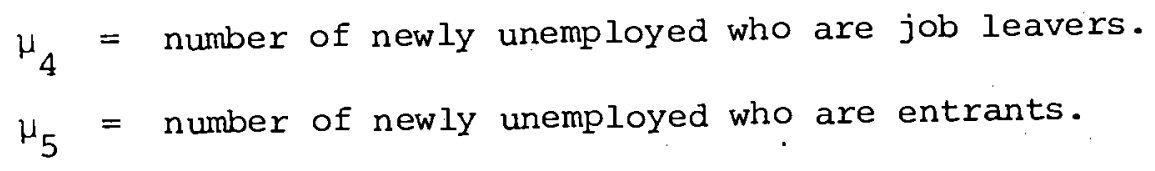

Incidence

A further decomposition of each of the 5 subgroups comprising the newly unemployed can be accomplished by recognizing that $\mu_{i}$ is equal to the product of a transition probability $\left(p_{i}\right)$ and the relevant stock of individuals $\left(S_{i}\right)$ from which the flow into unemployment originated.

$$
\mu_{i}=p_{i} s_{i}
$$

The relevant stock for $i=1$ to 4 is the number employed. For $i=5$, it is the number not in the labor force. $p_{i}$ may itself be broken up into the product of two probabilities. For example, the transition probability from employment into unemployment due to a quit is the product of the probability of an employed person quitting and the probability of unemployment conditional on having quit.

$$
p_{i}=y_{i} z_{i}
$$

The marginal probability of a separation from the previous state is $y_{i}$ and the associated conditional probability of being unemployed given a separation is $z_{i}$

Duration

The basic elements in Equations 1 through 3 refer to the incidence of (flow into) unemployment. In describing the other major component of 
unemployment, one speaks either of the flow out of unemployment, the continuation rate which is one minus that flow, or the duration of unemployment. The relation between the duration of unemployment associated with group $i$ of the unemployed $\left(d_{i}\right)$ and the continuation rates for those in group $i\left(r_{i, k}\right)$ is

$$
d_{i}=\sum_{k=0}^{\infty}\left[k \cdot r_{i, 0} \cdot r_{i, 1} \cdot r_{i, 2} \cdot \cdot r_{i, k-1}\left(1-r_{i, k}\right)\right]
$$

where $r_{i, 0}=1 . r_{i, k}$ is the probability that a person unemployed at the beginning of period $k$ for reason $i$ will also be unemployed during period $k+1$. The product of the $r_{i, k}$ 's in the first set of parentheses represents the probability of a person who becomes unemployed at the beginning of period 1 remaining unemployed throughout the periods before period $k$. $\left(1-r_{i, k}\right)$ is the probability of leaving unemployment at the end of period $k$, given that the individual was unemployed during that period.

Expanding the expression and collecting terms, we have

$$
d_{i}=\sum_{k=1}^{\infty}\left(\prod_{j=1}^{k} r_{i, k-j}\right)
$$

This is the expression for the duration of completed spells of unemployment. It will not be equal to the average duration of spells of unemployment in process such as one obtains from cross-section CPS data (assuming a steady 
state) unless $r$ does not vary with unemployment duration $(k) .^{1}$

Unemployment

Assuming a steady state, the expression for the total number who are unemployed in any period for reason $i$ is given by ${ }^{2}$

$$
u_{i}=\mu_{i} \sum_{k=1}^{\infty}\left(\prod_{j=1}^{k} r_{i, k-j}\right),
$$

where $r_{i, k-j}=1$ for $k-j=0$. The total number unemployed in subgroup $i$ is equal to the sum of the $\mu_{i}$ people who have just become unemployed, the fraction $r_{i, 1}$ of the $\mu_{i}$ people who first became unemployed one period before that, and so on. From Equation 4 it can be seen that the expression

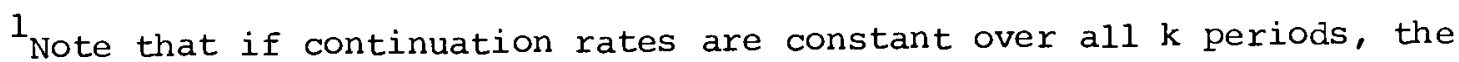
average duration of completed spells is simply $\frac{1}{1-r}$. The relation between the duration of interrupted spells and the duration of completed spells depends on the distribution of the $r_{i, k-j} \cdot$ Specifically, Stephen salant (1977) demonstrates formally that the relationship depends on the variance in the length of completed spells. He emphasizes that one cannot infer from the fact that current measured unemployment spells are longer for one group than for another that the completed spells will also be longer for the former group. On this subject, see also the papers by Hyman w. Kaitz (1970), Robert H. Frank (1978), Tony Lancaster (1979) and Stephen Nickell (1979).

Using the notation developed above, but dropping the subscript $i$, it can be shown that the expected length of an interrupted spell is given by

$$
D=\frac{\left.\sum_{k=1}^{\infty} \sum_{j=1}^{k} r_{k-j}\right)}{\sum_{k=1}^{\infty}\left(\prod_{j=1}^{r}\right)}
$$

where $r_{k-j}=1$ for $k-j \leq 0$. This will be equal to $\frac{1}{1-r}$ if $r$ is independent of duration.

2 For our purposes the assumption of a steady (Continued on page 9) 
to the right of $\mu_{i}$ in Equation 5 is equal to the expected duration of a completed spell of unemployment, $d_{i}$. Thus we have the well known result that in a steady state, the total number unemployed (for a particular reason) is equal to the product of incidence and duration of completed spells.

$$
\mathrm{U}_{i}=\mu_{i} \mathrm{~d}_{i}
$$

Overall unemployment can be obtained by sunming across the $i$ subgroups.

$$
U=\sum U_{i}
$$

UI and Elements of Unemployment

The effect of variations in unemployment insurance can be introduced in a general way by recognizing that the flow of newly unemployed in group $i$ $\left(\mu_{i}\right)$, the associated stocks of employed or those not in the labor force $\left(s_{i}\right)$, the transition probability $\left(\mathrm{p}_{i}\right)$, the marginal and conditional probabilities underlying $p_{i}\left(y_{i}\right.$ and $\left.z_{i}\right)$, the duration of unemployment $\left(d_{i}\right)$ [or the definitionally related probabilities--the continuation rates $\left.\left(r_{i, k-j}\right)\right]$ are all functions of parameters--yet to be specified--of the UI system, as well as other variables. Accordingly, Equations 2 and 6 may be differentiated to represent the effects of a given change in the UI system. Since the system of equations represents a steady state, differentiation corresponds

(Footnote 2 continued from page 8) state is adequate. If one were concerned with UI and stabilization policy, this assumption would have to be relaxed. It would also have to be relaxed to analyze the impact of changes in the UI system in the short run. 
to comparing steady states. Specifically we have

$$
u_{i}^{\prime}=\left(p_{i}^{\prime} s_{i} d_{i}+p_{i} s_{i}^{\prime} d_{i}+p_{i} s_{i} d_{i}^{\prime}\right)
$$

In other words, the impact of a change in a particular feature of the UI system on unemployment reflects its effect on the transition probability of becoming unemployed, its effect on the number of those either employed or not in the labor force and its effect on duration. But this impact also is determined by the basic level of the transition probability, the number of those employed or not in the labor force, and the average duration of unemployment.

Although the result is not shown, by differentiating Equation 3 and substituting for $\mathrm{p}_{i}$ and $\mathrm{p}_{i}^{\prime}$ in Equation 8, it is also possible to express the effect of changes in UI on unemployment as functions of the level and changes in the probabilities $y_{i}$ and $z_{i}$. In sum, it has been shown that the overall effect of a change in UI on unemployment may be expressed as functions of subsets of $\mu_{i}, p_{i}, s_{i}, d_{i}, y_{i}$ and $z_{i}$ and the partials of these measures with respect to a change in the UI system, $\mu_{i}^{\prime}, p_{i}^{\prime}, S_{i}^{\prime}$ $d_{i}^{\prime}, y_{i}^{\prime}$ and $z_{i}^{\prime}$. Since these elements are not all independent of one another, values for all of them are not required to evaluate the effect of a given change in the UI system on unemployment. Nevertheless, if we are to fully understand the effects of, the UI system on unemployment, we should understand its effects on each of these unemployment related flows. 
B. Features of the UI System

A second part of the analytical framework consists of a more detailed look at the policy parameters of the UI system. The two major categories into which the program features fall are benefits and taxes.

(1) To be eligible for benefits, the individual must have demonstrated an attachment to the labor force by having met requirements as to minimum earnings and/or length of employment in a covered job.

(2) The benefit structure is characterized by minimum and maximum levels.

(3) There is a schedule relating the level of benefits to past earnings. Potential duration of benefits may also vary with earnings history with the exact relation differing among states.

(4) There is a set of rules for determining qualification. Criteria include having an acceptable reason for separation from the job-an individual who has voluntarily separated without good cause may be disqualified from receiving benefits or may face a prolonged waiting period--and a requirement that the individual engage in active job search and be ready and willing to accept an offer of suitable work.

(5) During times of high unemployment, job search requirements may be relaxed and the period of potential benefits extended.

The UI system is financed by a 3.4 percent federal payroll tax. Credit is given against the federal tax for employer UI taxes paid to the state, provided that the state adopts an experience rated system. With the credit the federal tax is .7 percent of the taxable payroll. ${ }^{1}$ Distinguishing characteristics of the UI tax include the following:

(1) The UI tax is a payroll tax.

(2) There is a ceiling on taxable payroll, currently $\$ 6,000$ per covered worker, set by the federal government. However, states may raise the ceiling above this level.

1.2 percentage points of this tax is a temporary surcharge until the UI trust fund loans are repaid. The current estimate is that the surcharge will remain in force until the late 1980 's. 
(3) The tax paid on benalf of a worker who transfers from one employer to another during the taxable year is not transferable.

(4) According to the predominant system of experience rating, a firm's tax rate is based on the ratio of taxes collected in a reserve fund after charged benefits to the taxable payroll--where the taxable payroll consists of earnings up to $\$ 6,000$ for each covered employee. 1

(5) The tax schedules are characterized by minimum or maximum rates. After some point, the tax rate does not decline as benefit payments decrease so that for some firms, the tax contribution exceeds benefits drawn by their employees. Other firms never contribute as much as their employees draw.

(6) For those firms whose tax rates are experience rated, the adjustment in tax rates to benefits paid is made with a lag.

\section{Theoretical Linkages}

The third part of the analytical framework consists of categories derived from theory which indicate how and why the behavior of individuals and firms may be influenced by the UI system and its features. These categories provide "theoretical linkages" between the public policy and the outcome measure of interest. On the supply side of the market, we have the theory of labor leisure choice and the theory of occupational choice-including relevant considerations from the theory of human capital and compensating differentials. In addition, since there is uncertainty and perhaps also imperfect knowledge, both search theory and the theory of insurance are relevant. On the demand side of the market, there is the maximization hypothesis underiying thetheory of derived demand, relevant aspects of human capital theory as it affects the behavior of the firm and the theory of firm behavior in the face of uncertainty. Modifications of the theory to reflect the influence of labor market institutions such

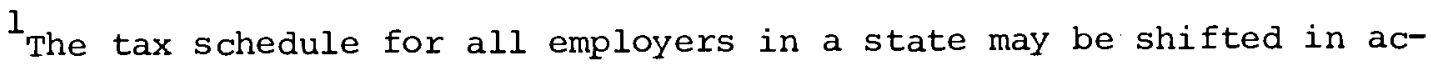
cordance with the current surplus or deficit position of the reserve fund for the state as a whole. 


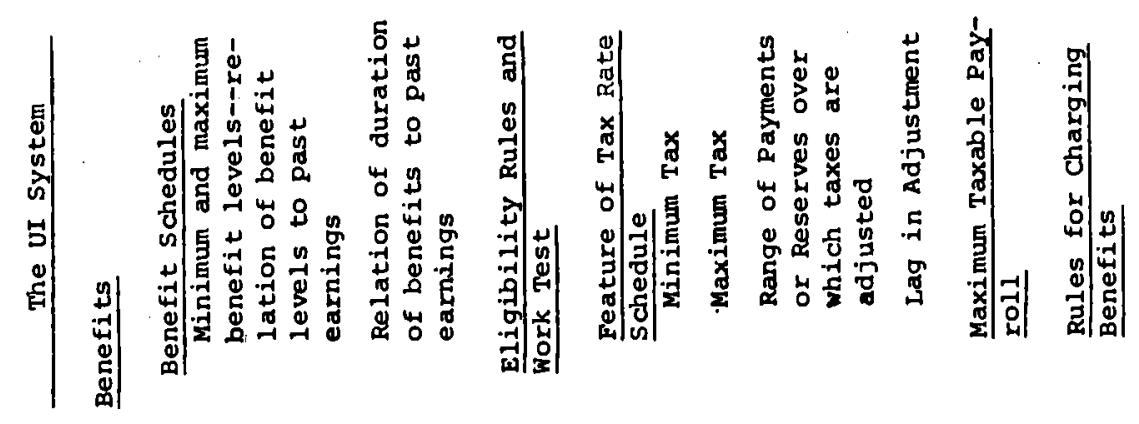
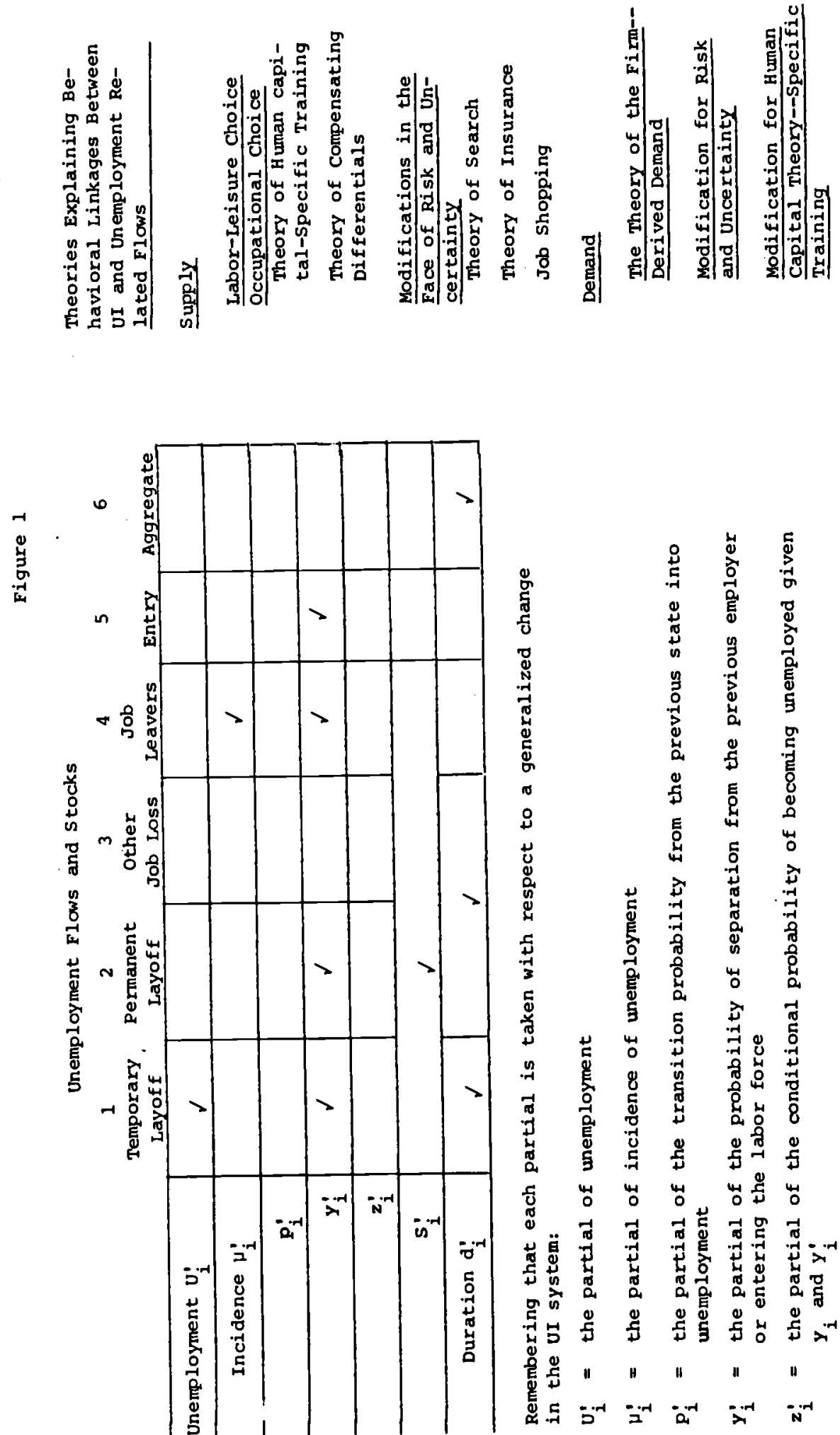

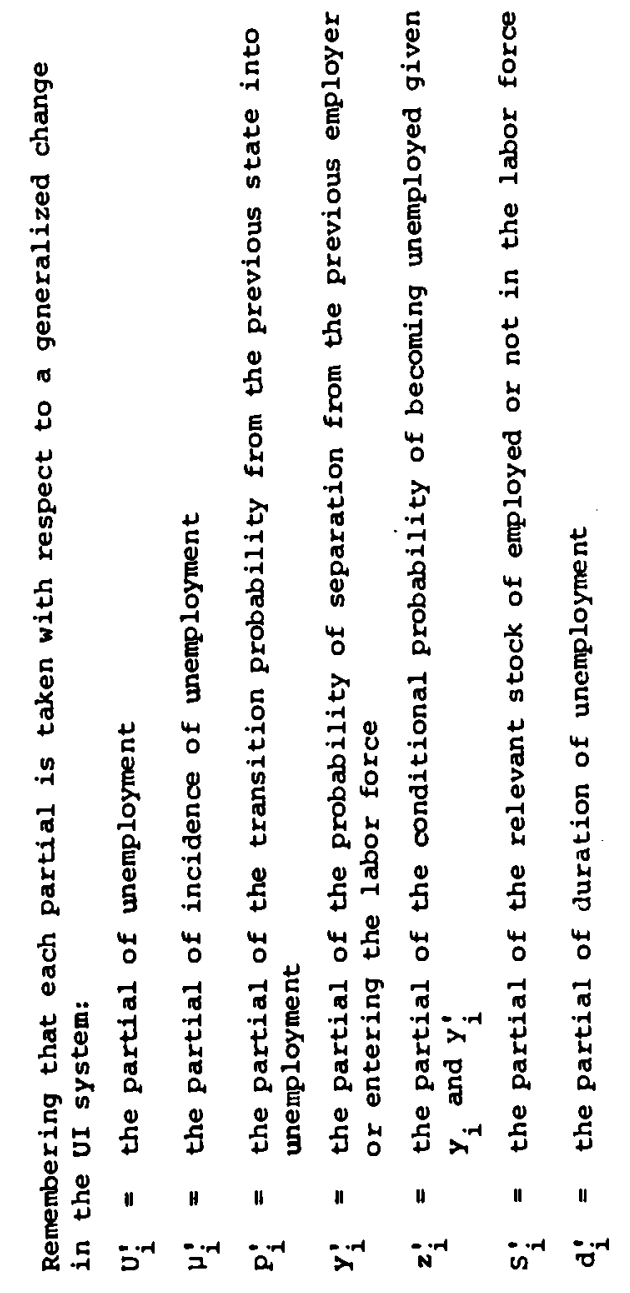

$\dot{x} \dot{0} \dot{0}$ 囟 $\dot{0}$ 
as unions will be relevant if they affect the way in which the UI program influences unemployment.

Figure 1 presents the basic features of the analytical framework. The matrix on the left-hand side of the figure has as its elements the partials of labor market flows with respect to variations in the parameters of the UI system. Two points may be made about this matrix. First, notice that the market flows relating UI to unemployment are listed hierarchically in column 1. Thus, it can be seen in column 1 of the matrix that to understand how UI affects unemployment, one need not have full information on each of the flows. For example, $y_{i}^{\prime}$ and $z_{i}^{\prime}$, the differences in the probabilities of separating from the previous state and of becoming unemployed given a previous separation, when weighted, determine the value of $\mathrm{p}_{i}^{\prime}$, the change in the transition rate from the previous state to unemployment associated with variation in some feature of the UI system. Second, the proceeding discussion implies that to aggregate the partials of more basic flows and determine their influence on unemployment, the partials must be weighted appropriately, e.g., as called for in equation 8 .

Each of the features of the UI system which may affect these flows is listed in the right-hand column of Figure 1. The middle column of Figure 1 reports the major behavioral linkages explaining how and why varying features of the UI system may change the unemployment related labor market flows. Much of the rest of this paper is concerned with filling in the details pertaining to the information in Figure 1 . If we could fill in the first row of the matrix in Figure 1 , it would mean that we knew what the overall 
effect of the unemployment insurance system on unemployment was. As things stand, we have most of the required inforamtion only for $U_{l}^{\prime}$, the difference in temporary layoff unemployment induced by the UI system. And even there, much more work is called for.

At this point, one might consider again the need to analyze the relation of the UI system to all of the flows which determine the level of unemployment by reason for unemployment. Instead of decomposing unemployment by reason into the more basic flows which comprise incidence, or duration, why not proceed directly to analyze the relation between the UI system and the level of unemployment by reason? The answer is that these basic labor market flows are not all determined by the same set of market forces. (Although, as will be noted, there are forces creating interdependence among a number of the flows, leading to behavioral relations that are more similar than one might, at first, think). Accordingly, the effect of estimating directly the relation between the UI system and the level of unemployment by reason (except, perhaps, the level of temporary layoff unemployment) is to obscure more basic underlying behavioral relations. In addition, any change in the relation among structural equations will have the effect of altering the reduced form relation explaining $U^{\prime}$ for reasons that cannot be determined unless each of the underlying structural relations and their relations to one another are understood.

It can be seen in Figure 1 that certain boxes corresponding to different unemployment related flows, including that for $U_{i}$, have been checked. These checks indicate that we have some reasonably reliable information -- either at the empirical or theoretical level -- concerning the impact of some 
features of the UI system on the relevant flow. A check means that we know at least a part of the relevant story -- not that all or most of the story is available.

The discussion in the following section is organized according to the elements of the matrix in Figure 1. It starts in row 1 , column 1 and proceeds element by element across the rows.

\section{Recent Developments in the Literature}

A. Impact of UI on the Level of Unemployment: $U_{i}^{\prime}$

\section{Temporary Layoff Unemployment: $U_{i}^{\prime}$}

To begin the discussion, focus on the impact of UI on temporary layoff unemployment, which falls in the cell in row 1 , column 1 of the matrix in Figure 1. ${ }^{1}$ Relevant features of the UI system affecting temporary layoff unemployment include both the benefit and tax schedules. Since temporary layoff is usually of short duration, factors influencing the potential duration of benefits are not relevant. Nor is the work test likely to be important, at least for those with a firm date of recall. The important feature is the level of benefits as determined by the workers past earnings and employment history, and in some cases, number of dependents.

On the tax side, the amount of UI payroll taxes paid by a firm ( $T$ ) is equal to the product of the tax rate $(\lambda)$ and the taxable payroll (TP)

$$
T=\lambda \cdot T P
$$

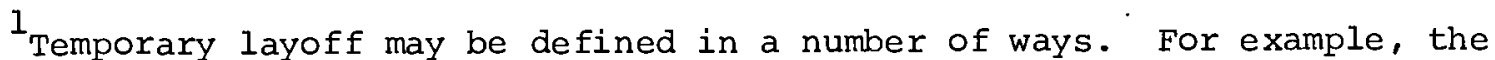
category may include only those with a firm date of recall, those who have a firm date of recall or expect to be recalled, or it may be defined in ex post terms as those who were recalled. The definition differs among studies. 
The taxable payroll is equal to the sum of the taxable wages paid to each worker during each calendar year, with the ceiling on taxable wages per worker currently equal to $\$ 6000$. A temporary layoff will not affect directly the taxable payroll unless the worker will earn less than $\$ 6000$. However, if the quit rate from temporary layoff is higher than it is for employed workers, and if those who quit are replaced, higher temporary layoff rates will be associated with higher taxable payroll. ${ }^{l}$ The firm loses credit for taxes paid on behalf of the worker who quit and must pay the tax on earnings, up to $\$ 6000$, paid during that same year to the worker's replacement.

The UI tax rate will vary when workers are temporarily laid off and are paid benefits as long as the rate falls within the range where it is experience rated. To see how the tax rate is adjusted in light of the

${ }^{1}$ Donald O. Parsons (1977, p. 199) notes that attrition from the total of those on layoff status is about 10 to 20 percent per month. 
firm's experience, consider the reserve ratio system which is in place in 32 states. $^{1}$ The idea of the reserve ratio system of experience rating is to have the tax rate vary with the amount of reserves in the firm's account relative to the firm's taxable payroll. Reserves are accumulated from taxes paid in excess of benefits, or may be negative if benefits paid exceed taxes for a long enough period. The rate increases (decreases) whenever benefits paid to the firm's employees exceed (fall below) tax receipts from the firm. The tax rates are adjusted along a schedule until the flow of benefits and flow of taxes are equalized, or until it hits a ceiling or floor.

To help describe the relation of the tax rate to labor turnover, a simplified version of a diagram from a study by Frank Brechling and Christopher Jehn (1978) is presented in Figure 2. The tax schedule is experience rates along segment de and at the point of the discontinuous jump, bc. ${ }^{2}$

Figure 2

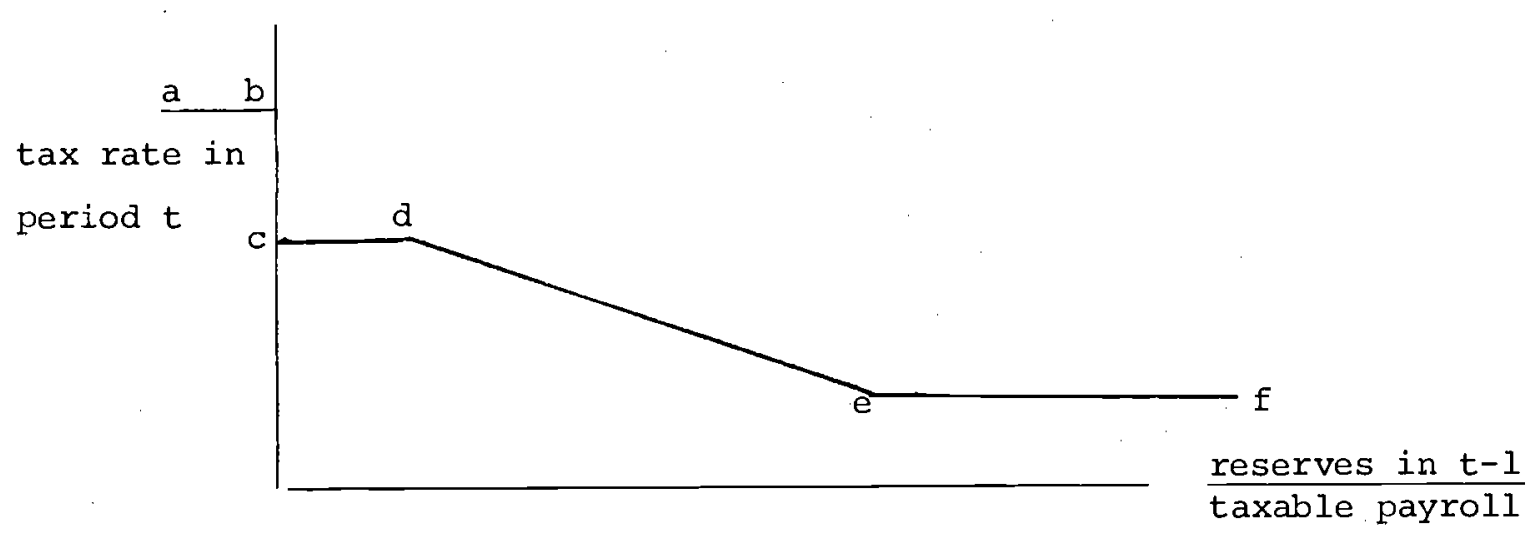

${ }^{1}$ Systems in operation in the other states are analyzed by Eleanor Brown (1979). Brown also considers the tax costs of changing the size of the firm's labor force.

2 Actual tax schedules, as discussed by Brechling and Jehn and Topel and Welch (1979), may be more complex. For example, the segment de is not smooth, but consists of discontinuous jumps. In some cases, the tax rate may vary with reserves even in the range of negative reserves. For a more complete description, see the very thorough study by Joseph M. Becker (1972). 
It can be seen that firms located on the segments $a b, c d$, and ef have tax rates which are not experience rated, althougn, as noted there may be some variation in the tax rate due to the discontinuous jump, bc. Firms with tax rates which are not experience rated have extreme turnover rates which are either relatively very high or relatively very low. A firm whose employees consistently collect benefits that exceed the amount of payroll taxes that are generated when the maximum UI tax rate is chargedagainst its taxable payroll not only has negative reserves, but in the absence of a floor, would have ever declining reserves. A firm whose workers infrequently receive UI benefits may consistently generate more revenue than its workers receive in benefits. Thus it would have positive reserves and unless the minimum tax rate were zero, in the absence of a ceiling the firm could have ever growing reserves. ${ }^{l}$ The rate of adjustment in tax rates brought about by the effects of changing turnover on reserves determines the speed with which the tax flow changes in response to changes in benefits, and thus the speed of adjustment of the system. The steeper is de, the more rapid is the adjustment.

It is worth restating how temporary layoffs affect payroll taxes. As long as actual earnings are well above the maximum earnings subject to the tax, except for quits from layoffs there is no effect of temporary layoffs on taxable payroll. Moreover, if the firm's tax rate is at the ceiling or the floor, the tax rate is not affected by temporary layoffs either. The firms which pay higher taxes when temporarily laying off their work force are those with a tax rate within the range where it is experience rated. For those firms, their tax rate is adjusted, although with a lag, so that in the steady state, the flow of taxes offsets the flow of benefits paid periodically to those on temporary layoff.

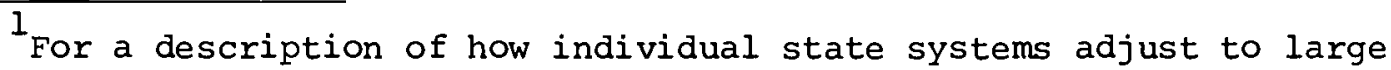
accumulated surplusses or deficits in the firms' accounts, see Becker (1972). 
The Basic Theory of UI and Temporary Layoff Unemployment

Martin Feldstein's (1976) theoretical analysis explores the implications of imperfect experience rating and a subsidy to recipients of UI payments which is due to the tax free status of UI benefits. (Current tax law exempts UI payments from the income tax for those earning less than $\$ 20,000$. on the supply side, the linkage between the UI system and unemployment is provided by the labor-leisure choice model in the context of an analysis of compensating differentials. On the demand side, the analysis is grounded in the theory of the firm--derived demand.

To simulate the effects of fluctuations in output demand, it is assumed in the model that market price is depressed for a specified fraction of the year. The firm is able to sell all that it produces at whatever the current price is, but does not store output for later sale. To focus the analysis on temporary layoff unemployment, it is also assumed that workers are permanently attached to the firm. Then, constraining the money wages paid to be the same in the on and off season, Feldstein asks what combination of wage and employment policy would minimize labor costs, and what difference unemployment insurance makes to the calculation. Without addressing directly the question of the shifting of the payroll tax, the model allows UI tax payments to be a function of total UI benefits paid. The value of UI benefits net of the income tax and the UI payroll tax enters into the worker's calculations.

Feldstein's analysis explains why firms which experience seasonal fluctuations in demand and face UI tax schedules that are.imperfectly experience rated are encouraged to lay off more workers than they would 
if the firm paid the full cost of benefits received by their workers -i.e., if there were complete experience rating. The income tax exemption for UI benefits is also shows to encourage layoffs.

It is interesting to take note of the very simple effect UI has in a static model in which there is no uncertainty and a supply curve to the firm that is perfectly elastic in terms of utility equivalents - - i.e., in which labor supply to the firm is perfectly elastic, but the wage (height of the elastic labor supply curve) is adjusted to reflect the value of nonwage elements of the compensation package. If UI benefits are taxable as ordinary income, the effect of unemployment is to reduce wages, replacing a compensating differential which otherwise would arise to equate returns to those in occupations with and without unemployment. A fully experience rated tax raises the firm's costs by as much as the UI benefits reduce them, leaving no net effect of a perfectly rated UI system.

Feldstein's study provides a framework which is extremely useful for understanding the impact of UI taxes in the context of a market structure in which possibilities for substitution exist both on the supply and demand sides of the labor market. ${ }^{l}$ A point stressed in the paper is that if a

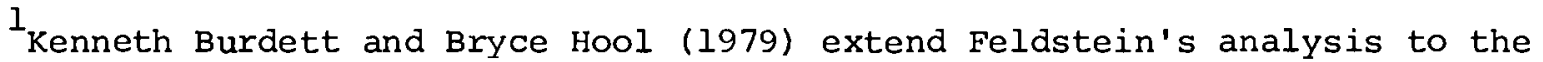
case where workers face an imperfect capital market, limiting their ability to borrow and lend. In such a circumstance, the pattern of consumption over time becomes tied to the pattern of the earnings stream,rather than simply to its present value. UI may then substitute for the rolc played by the capital market, allowing consumption to take on a more ideal pattern over time, even in the face of unemployment. Daniel Hamermesh (1979b) finds that the true situation lies between the extremes of perfect and imperfect capital markets. Thus, while for some the funds provided by UI effectively relax a borrowing constraint and allow increased current consumption, others treat the benefits as additions to permanent income, increasing consumption in current and future periods. 
long-run view is taken of choice on the supply side, much of temporary layoff unemployment is voluntary. It results from the choice of an occupation with a known expected unemployment experience. This is so even though any particular incidence of unemployment may be involuntary .

While the theory is applied to analyze temporary layoffs, there is no reason why this general approach may not be used to explain that portion of permanent layoffs which are recurrent and expected--e.g., in the construction industry. Some required mofidifications are discussed below. Martin Baily (1977a) has written a paper which differs in some detail from, but is closely related to Feldstein's. It assumes a two-period model in which workers formulate expectations as to the firm's behavior in response to demand fluctuations. The supply price of labor is based on these expectations and opportunities elsewhere. The firm in Baily's model is free to adjust hiring and hours worked in both periods. ${ }^{1}$ As in Feldstein's paper, demand fluctuations are represented by variations in output price. However, in this model, workers may search for a new job from layoff, but at a cost. They will do so if the expected benefits warrant it.

The Feldstein-Baily theoretical structure is elaborated on in a paper by Frank Brechling (1979), in which he includes a complex specification for the UI payroll tax structure and examines the effect of the UI system on the firm's incentives to engage in temporary layoffs. The Brechling analysis concentrates on the demand side of the market.

John Abowd and Orley Ashenfelter (1979) analyze in further detail the roles of compensating differentials for unemployment and of unemployment

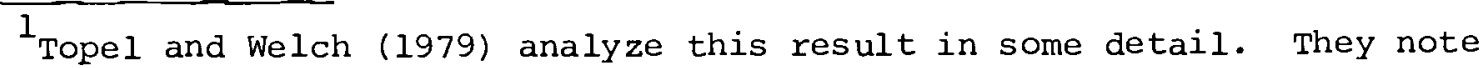
that subsidized UI benefits may lead firms to reduce weeks per year worked per employee, while expanding the size of the labor force. 
insurance in influencing labor supply. In their mode?, it is recognized explicitly that workers are not free to choose hours of work for those jobs which are characterized by involuntary unemployment. The constraint is built into the specification of the labor supply curve.

Looking back at the list of theoretical linkages in Figure 1 and comparing it to the behavior analyzed in the papers mentioned above, it appears that the impact of the UI system on temporary layoff has yet to be analyzed in a model which fully treats two important aspects of behavior -adjustments to risk and uncertainty and specific training. The role of UI as insurance has received some attention (see, for example, Frank Stafford's (1977) paper and the discussions by Topel and Welch (1979) and Abowd and Ashenfelter (1979), , but have yet to be incorporated in a full model analyzing the impact of UI on temporary layoffs which considers both the supply and demand sides of the market. Similarly, interactions between specific training and unemployment insurance and the reasons why these may affect the probability of temporary layoff have not been analyzed adequately. An important reason for believing that specific training and unemployment insurance may interact is that imperfect experience rating reduces the cost to the firm of placing workers on recall layoff rather than keeping them on the payroll but underemployed. Since workers with specific training are the ones the firm would most like to retain in the long run, and the UI subsidy reduces the cost of retaining them, it may lower the costs of maintining a work force which has a high level of specific training.

Empirical Analyses of Temporary Layoff Unemployment

Feldstein (1978) estimates the relation of the temporary layoff unemployment rate to predicted UI benefit-replacement rates (benefit-wage 
ratios) and finds strong evidence of an important relationship. ${ }^{1}$ More specifically, he estimates an equation based on data from the March 1971 Current Population Survey. The dependent variable is a binary variable indicating whether the individual is on temporary layoff. The independent variables incorporate predicted values of UI benefits as a percent of net wages, which are available both for those who were and were not unemployed during the period of observation, demographic characteristics and measures indicating occupation industry and union membership. Ordinary least squares is used.

The temporary unemployment rate for the sample was 1.6 percent. Coefficient estimates for various versions of the benefit measure suggest that in comparison with no UI system, the temporary layoff unemployment rate has been raised by roughly one-half by the current, average level of benefits. ${ }^{2}$ Variation in UI benefits is found to have the greatest effect when benefitreplacement rates lie above 30 to 50 percent. No direct measure of the degree of experience rating is incorporated in Feldstein's estimates. The exact interpretation of the coefficient of the UI benefit measure -- i.e., what part of the variation in temporary layoffs should be attributed to which parameters of the UI benefit and tax schedules -- depends on the relation among the parameters and the resulting relation between the degree of experience rating and benefit levels.

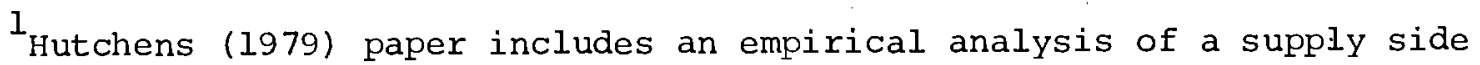
relation consistent with the structural supply equation in the Baily-Feldstein model. His analysis considers both temporary and permanent layoffs.

2 Remember the caveat noted earlier. If there were no public UI system, some alternative system with unknown characteristics would have emerged. That system, however, is likely to have been fully experience rated, so that UI benefits and tax payments would not only match at the aggregate (state) level, as they now do over the long term, but there would be no crosssubsidy among firms within each state. 
What one cannot tell from these results is the importance of worker attachment to the firm. Feldstein's model assumes permanent attachment. As noted, taxable payroll is unlikely to be affected in that circumstance by temporary layoff. To the extent that seasonal separations in construction are permanent, taxable payroll may be increased by turnover. This phenomenon is further analyzed in the discussion of permanent layoffs. ${ }^{1}$ Unemployment for Reasons Other Than Temporary Layoff: $U_{2}^{\prime}, U_{3}^{\prime}, U_{4}^{\prime}, U_{5}^{\prime}$ Looking across row 1 of the Table in Figure 1 , the other unemployment measures which may be affected by the UI system are unemployment due to indefinite layoff, other job loss, job leaving or entry. As noted in the introduction to this section, no direct information is available on the effect of UI on the level of unemployment for each of these reasons. Information is available on the impact of UI on the underlying flows found in rows 2 to 5 of the table. We turn now to a discussion of that information.

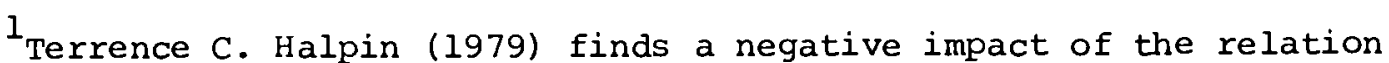
of taxable to total wage base on seasonal fluctuations in construction employment, but not on seasonal fluctuations in employment for two other industries he analyzes--women's, misses' and junior's outerwear, and millwork, plywood, veneer and other prefabricated wood products. There is a further discussion of these results below. 
B. Impact of UI on the Incidence of Unemployment: $\mu_{i}^{\prime}$ (row 2)

Stephen T. Marston's (1979) study of the impact of the UI system on the incidence of unemployment for those who quit is the only study to be classified as falling in one of the categories indicated in row 2 -i.e., to be concerned directly with the impact of the UI system on the incidence of unemployment. In the case of those who quit, the state's eligibility rules are a major determinant of the expected value of UI benefits. In some states, the waiting period is prolonged for job leavers. In others, they are barred from collecting benefits at all.

Marston uses as a measure of the value of UI benefits a measure of benefits weighted by the fraction of the spell over which an individual can collect. His regressions are based on pooled CPS data for three years. Independent variables include demographic factors, labor market variables including the wage and broad occupational dummies. Marston can find no significant effect of the expected benefit level on quits. Thus there is no evidence that making UI benefits available to those who quit encourages quits.

The theoretical basis for Marston's analysis of quits is rooted in the supply side of the market. An analysis based on the demand side is presented by Brechling. That study, which is discussed in the appropriate section below, focuses on the incentives of the firm to follow policies which lower the quit rate -- a component of the incidence of quit unemployment. Neither the theoretical framework in Marston's study nor 
the empirical analysis incorporates the role of specific training (job tenure). 1

c. The Impact of UI on Transition Probabilities into Unemployment: $\mathrm{P}_{i}^{\prime}$ As is apparent from the table in Figure 1, none of the relevant studies has examined the impact of UI on this transition probability. As will be seen, however, there is important, related theoretical and empirical work at a slightly more disaggregated level of analysis -- i.e. on the probability of leaving employment or not in labor force status. D. The Probability of Leaving Employment or Not in the Labor Force Status: $Y_{i}^{\prime}$ Incidence of Temporary Layoffs: $y_{1}^{\prime}$

Using BLS establishment survey data and data pertaining to certain parameters of state UI systems, Frank Brechling (1979) attempts a further test of the Feldstein-Baily analysis of the relation of UI to the incidence of temporary layoffs. He points out that the existence of a feedback effect of UI benefits on wages is a key to the prediction of the Baily-Feldstein model that with current income tax treatment of UI benefits and imperfect experience rating, an increase in UI benefits increases layoffs. In the absence of such a feedback effect, the higher the benefits, the higher the cost of temporary layoffs to those firms which are not at the maximum tax rate. But a firm whose workers do not value the higher UI benefits will not face a lower wage to compensate (or more than compensate) for the tax costs. Thus the firm has less incentive to engage in temporary layoffs if there is no feedback effect of UI benefits on wages.

\footnotetext{
${ }^{1}$ Leighton and Mincer (1979) present an analysis of the implications of job tenure for quits. J. Peter Mattila (1974) has pointed to the tendency for those who quit to move directly from one job to another -- underlining the importance of distinguishing between the incidence of quit related unemployment and the probability of a quit.
} 
Brechling does not standardize for many of the exogenous measures included in Feldstein's empirical analysis (1978). Nor is there any standardization for the role of human capital. He does, however, specify in more detail than in Feldstein the role of the parameters which determine the shape of the UI payroll tax function as illustrated in Figure 2 above, noting, in addition, that the parameter of the UI system employed by Feldstein -- the fraction of benefits charged to the firm -- may be endogenous to the analysis.

Findings from Brechling's empirical analysis are (as Brechling views them), only a first, rough attempt at estimation. Not only are there the ommissions noted above, but dependent variables refer to aggregated categories which may include permanent layoffs. Moreover, the benefit measure used in industry equations refers to the average value for the state. It is not a parameter from the benefit schedule, nor is it calculated separately by industry. Nevertheless, it is of interest to note that the coefficient estimates which indicate the impact of benefits and tax parameters are consistent with a Baily-Feldstein type of model. ${ }^{2}$

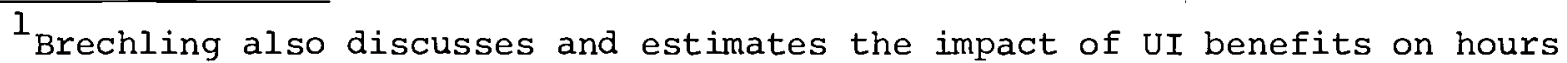
worked and on duration. The duration results are discussed in the relevant section below.

2 Brechling finds a positive effect of the benefit level on layoffs, with a t-ratio greater than 1.5 in 8 of 16 industries. But although the sign is positive, the t-statistic is less than 1.5 for the benefit variable in an equation computed with data for all of the industries taken together. An equal number of positive and negative coefficients with t's above 1.5 is estimated for benefits in the equations with recalls or hours worked specified as the dependent variable. 
The findings with respect to tax rates support the view that layoffs and recalls are responsive to the degree of experience rating. While no measures are incorporated in Brechling's study to indicate how many firms face, or what fraction of benefits paid are to workers of firms facing, the maximum or minimum tax rates, these findings indicate that variation in the parameters of the tax rate schedule have the expected influence. An increase in the maximum tax increases the range for experience rating and is associated with reduced layoffs and rehires. An increase in the minimum tax rate reduces the range over which experience rating applies, and as would be expected, is found to increase the rates of layoffs and rehires. ${ }^{1}$

Incidence of Farmanent LayoffS, $Y_{2}^{\prime}:$ The Theory

It has been noted above that payroll taxes paid are equal to the product of the tax rate and taxable payroll. Each of these elements may be influenced by the number (flow) of permanent layoffs. The basic theoretical work analyzing this relationship is due to Brechling (1977). The new element there is the relation between turnover rates and the taxable payroll--a relation that may be traced to the effect of the ceiling on earnings subject to the payroll tax. When a worker is separated from

In the layoff equations for a total of 16 industries, the measure of the ceiling tax rate has a negative coefficient with a $t$ statistic above 1.5 in 11 industries and a positive coefficient with a $t$ above 1.5 in none. In the rehire equations the corresponding numbers are 6 and 0 . The minimum tax rate has a positive coefficient with a $t$ above 1.5 in 5 equations explaining layoffs and a negative coefficient with a $t$ above 1.5 in 2 equations. For rehires the numbers for the coefficients of the minimum tax variable are 6 and 3 . 
the firm and not replaced, if the worker has not yet earned the full $\$ 6000$ during the calendar year, the separation reduces the taxable payroll. If $\$ 6000$ has already been earned, the layoff does not immediately reduce the taxable payroll, but will beginning the next year. Paying a benefit to the worker who separates (e.g., because he does not locate a job immediately after layoff) reduces the size of the reserve fund. If reserves fall relative to taxable payroll, as long as the tax rate is on the portion of the schedule that is experience rated, there subsequently will be an adjustment in the tax rate. If the tax rate is not experience rated, the only effect of the layoff on the firm (related to the UI system) is that taxes to be paid are reduced because the taxable payroll is reduced.

Turn now to the case of recurring permanent layoffs where, at some time after the layoff, the worker is replaced. How might such layoffs with replacement occur? In some industries, e.g., construction, permanent layoffs and separation from the contractor commonly follow the completion of a job. More generally, quits from temporary layoff turn them into permanent layoffs expost. ${ }^{1} \quad$ But a worker let go as a result of a downward fluctuation in demand may also be replaced when that fluctuation is reversed.

Brechling has analyzed the incentive, for the firm to reduce turnover - an incentive created by the existence of a ceiling on wages paid to an individual that are subject to a payroll tax. The reason for this

${ }^{1}$ Quits from layoff are examined by John M. Barron and Wesley Mellow, (1980). 
incentive is as follows. A firm cannot claim credit for the tax paid during the calendar year by another employer on behalf of a newly hired employee. Nor when calculating the tax to be paid on behalf of a worker's replacement can it claim credit for the tax it paid during the calendar year on behalf of an employee who has since departed. As long as a worker's wage exceeds the maximum yearly wage subject to the UI tax, some of the worker's earnings will be tax free. But if the worker turns over during the year and is replaced, a tax must be paid on the earnings of both the worker who left and the replacement. ${ }^{l}$ This means there is a penalty for turnover even if the workers who leave experience no unemployment before securing a new job, or if, because of their unemployment history, workers who leave are ineligible for UI benefits. ${ }^{2}$ Because of

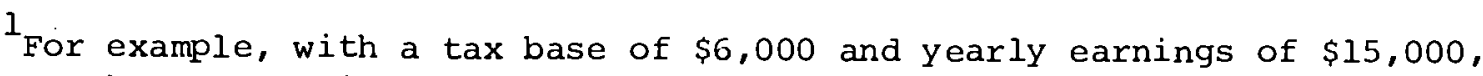
if the worker stays with the firm for the full year, tax must be paid on $\$ 6,000$ of earnings. If a worker quits or is dismissed in the middle of the year and is replaced, $\$ 12,000$ of the earnings paid for a single year of work is subject to the tax. A turnover with replacement that occurs near the beginning or end of the year may involve a smaller cost to the firm than one in the middle of the year.

2 Brechling demonstrates that at a taxable wage base equal to one-half of the worker's yearly earnings, the firm has the greatest incentive to reduce turnover. The incentive provided by the relation between permanent turnover and the taxable payroll is strongest in the case of firms which are subject to the maximum or minimum tax rates. For in this case, there is no initial balance between the flow of UI benefits paid and the flow of UI taxes. Thus, an increase in the taxable payroll associated with higher turnover will raise not just the stock of reserves, but the yearly flow of taxes into the UI system. This will be so whether or not higher permanent turnover is associated with higher benefit payments. 
the relation between separation rate and the amount of the wage bill subject to tax, a rise in the separation rate due to permanent layoffs may affect the payroll tax costs to the firm whether or not there is perfect experience rating. But the nature of the effect will depend on whether the firm's current tax rate is experience rated.

These relations can be seen most easily by considering payroll taxes in a steady state. Following Brechling, along the experience rated portion of the tax schedule, the tax rate $(\lambda)$ is given by

$$
\lambda=a-s \frac{R}{T P}
$$

where $a$ is the intercept of the experience rated portion of the tax schedule in Figure 2 and $s$ is its slope. $R$ is the absolute amount of reserves. As noted previously, TP is the firm's taxable payroll. If the steady state equilibrium occurs along the experience rated portion of the tax schedule, the flow of taxes $(T)$ and benefits (B) are equalized

$$
\lambda \cdot \mathrm{TP}=\mathrm{B}
$$

Substituting into the equilibrium condition the equation for the tax rate, reserves in the steady state are given by

$$
R=\frac{1}{s}(\operatorname{aTP}-B)
$$

The tax rate is simply 


$$
\lambda=\frac{\mathrm{B}}{\mathrm{TP}}
$$

Since increased turnover rates raise the taxable payroll, in the steady state, higher turnover raises the required stock of reserves and may lower the tax rate. As long as the tax rate remains experience rated, the per period flow of taxes changes only in accordance with any addition to charged benefits associated with higher turnover.

The above discussion assumes that the firm's tax rate is experience rated. With a turnover rate too high for experience rating (for firms on the left-hand portion of the tax schedule), the tax flow in equilibrium is less than the benefit flow,

$$
\lambda \cdot \mathrm{TP}<\mathrm{B} .
$$

The opposite is true for firms (on the right-hand side of the schedule) with very low turnover. For both groups, anything that increases the taxable payroll will increase the flow of taxes. Thus, an increase in the per period rates of permanent layoff will raise the flow of taxes, although it will not affect the tax rate.

Note that quit rates from layoff are likely to be higher the further away the expected recall date and the less firm the prospect for recall. Since the value of uI benefits drawn by a worker varies negatively with the quit rate from layoff, other things the same, firms with no experience rating will have the greatest incentive to 
offer a certain date of recall and avoid the increase in payroll tax costs associated with turnover and replacement.

Incidence of Permanent Layoffs, y': Empirical Evidence

To test for any effects of the ceiling on taxable payroll and parameters of the tax structure on turnover, Frank Brechling and Christopher Jehn (1978) estimate equations with turnover rates as dependent variables and maximum taxable payroll and tax parameters as independent variables. ${ }^{1}$ Their data is from the establishment survey and is aggregated into categories by two digit manufacturing industry, state and year. They do not have separate data on rates of temporary and permanent layoffs, but in addition to information on total layoff rates they know the accession and rehire rates. The parameters of the tax rate schedule are found to have effects in the expected direction. These effects are very similar to those noted in the preceeding discussion of Brechling's findings in his paper on temporary layoffs. The impact of the ceiling on earnings subject to the UI payroll tax is also in the expected direction. As the theory leads one to expect, the greatest impact on permanent turnover occurs where the ceiling on wages subject to the UI tax is roughly one half of average wages. These results are especially strong for quits and are discussed below.

$1_{\text {An }}$ intermediate step in studying the effects of the tax structure and experience rating on turnover is to determine the distribution of firms along the segments of the tax schedule in Figure 2. For evidence on the amount of benefits paid to workers from firms with tax rates that are not experience rated, see Becker (1972) and Topel and Welch (1979). 
Incidence of Permanent Layoffs, $y_{2}^{\prime}$ : Remaining Issues

Brechling and Jehn's study is rooted in demand theory. To gain a more complete understanding of the effects of the UI tax system and imperfect experience rating on permanent layoffs, it will be necessary to build into their model a supply side equation indicating the impact of UI benefits and the probability of layoffs on the wage. This is essentially the strategy Brechling followed in attempting to integrate his work on temporary layoffs with that of Feldstein.

A supply side analysis which could be merged with Brechling's demand side framework to make a more complete structural model is contained in Robert Hutchens' (1979) paper. He analyzes the tradeoff on the supply side between wages and the probability of a layoff, incorporating into his analysis the role of UI benefits. ${ }^{1}$

What other factors should be brought into the discussion of the relation of the UI system to permanent layoff? Consider in this context the role of specific training. It has already been mentioned that there is a complementary relationship between imperfect experience rating, temporary layoffs and specific training because imperfect experience rating subsidizes temporary layoffs and reduces the cost of retaining specifically

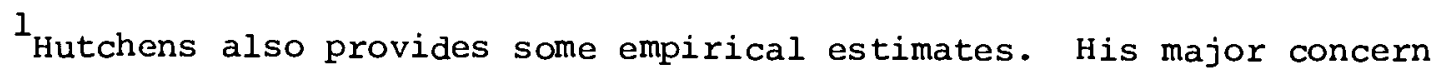
is with the tradeoff between layoffs and wages. Accordingly, his investigation of the impact of the UI system is not very detailed. His results suggest that more generous UI benefits are associated with higher probabilities of layoff. 
trained workers during periods of depressed demand. There are also other reasons why the UI system and specific training interact to influence jointly the firm's layoff policies. First, a tax on earnings encourages the substitution of untaxed for taxed inputs. A tax on a part of earnings encourages the substitution of untaxed for taxed labor--e.g., skilled for unskilled workers, since a larger part of the earnings of the skilled will be tax free (John Pencaval, 1970). Investment in specific training provides returns to the firm that are not subject to the payroll tax, since such investment and associated compensation policy raise worker productivity by more than the wage. In addition, to the extent that specific training adds to workers' earnings, it may be expected to do so in a range that is high enough not to be subject to the UI payroll tax. For this reason, UI may encourage further investment in specific training, thereby reducing the incidence of indefinite layoffs, separations for other reasons and quits.

Second, as Brechling points out, the cost of turnover is increased where there is a ceiling on the amount of wages subject to the payroll tax. To the extent that firms share the benefits of specific training with the workers, and in that way reduce turnover, specific training will also reduce the cost to the firm of the UI payroll tax. ${ }^{1}$ Thus, specific training provides an added benefit to the firm where the UT system exists and is financed by a payroll tax system with a ceiling on taxable wage. Third, to the extent that: a) the UI system encourages more extensive

\footnotetext{
licholas M. Kiefer and George R. Neumann (1979) find that longer past job tenure is associated with a larger decline in the reemployment wage of those separated, implying that the loss of specific training to job changers is greater for those who spent more time with their last employer.
} 
search and brings about more perfect matches between potential employees and jobs, and b) firms are more willing to invest in specific training the more perfect the match, the UI system may encourage investment in specific training. An implication, noted again in discussing implications for future research, is that the interaction between the UI system and specific training might reduce the incidence of job separation and increase job tenure.

One final point germane to a discussion of the impact of the UI system on layoffs is suggested by comparing the list of theoretical linkages between the UI system and unemployment related market flows listed in Figure 1 with the theoretical linkages considered in the studies reviewed above. The models already discussed---those analyzing the influence of both temporary and permanent layoffs---assume that firms and workers are risk neutral. They generally ignore any role for pure insurance. A more complete approach would consider the relation of UI to layoffs, occupational choice or firm hiring and inventory policy in a world in which individuals and firms prefer to avoid risk. Martin Baily (19770) and Frank Stafford (1977) provide relevant discussions. Topel and Welch (1979) also discuss relevant material on the role of unemployment insurance as insurance.

Incidence of Quits: $y_{4}^{\prime}$

From the relation of the UI system to permanent layoff, we turn now to consider the next labor market flow noted in the analytical framework for which any relevant information is available--i.e., the incidence of quits. In discussing studies of the relation of the UI system to the 
probabiliby of quitting and becoming unemployed, mention was made of Marston's (1979) study---a study which considers only behavior on the supply side of the market. Effects of the UI system on the firm's incentive to pursue policies which reduce the incidence of quits is considered by Brechling (1977). As was true in his analysis of permanent layoffs, of central concern in Brechling!s study is the incentive created by the impact of turnover on taxable payroll. In this analysis, however, it plays the central role. The reason is that benefits paid to someone who quits are not normally chargeable to the firm where the person last worked (Becker, 1972). Accordingly, the payroll tax rate will not change as a direct result of any benefits drawn by the person who quits. The only route by which such turnover can affect payroll tax costs is through its impact on taxable payroll. What does this mean for the relation of the firm's costs to the quit rate? As has been pointed out, the steady state condition for equilibrium in the UI system for firms with tax rates on the experience rated segment of their tax schedule is that the flow of tax payments equal the flow of benefit payments. Since quits raise taxable payroll in the same way that permanent layoffs do, yet the flow of tax payments remains unchanged for experience rated firms, this must mean that the tax rate varies negatively with quits in proportion to the positive variation in taxable payroll. 1

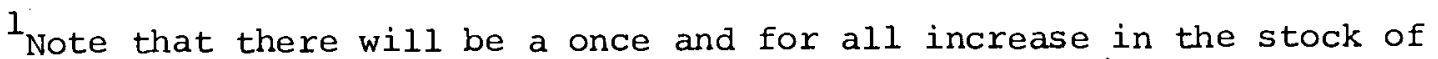
required reserves associated with higher quit rates for a firm with a tax rate that is on the experience rated portion of the tax schedule. 
of course, if the tax rate is not on the experience rated portion of the tax schedule, then the flow of tax payments will be increased as quits increase, providing the firm with an incentive to reduce quits by adjusting hiring or personnel policies or compensation. It should be stressed that this taxable payroll effect attributable to the $\$ 6000$ ceiling on taxable payroll provides an incentive to reduce turnover even in the absence of chargeable benefits and is very much magnified where there is an absence of experience rating.

One part of the Brechling and Jehn study noted earlier uses data on turnover in manufacturing by state and year to analyze the relation of parameters of the UI tax system and of the ceiling on taxable payroll in the state to the incidence of quits. The most impressive results in the quit equation are for the effect of the ceiling on taxable payroll. Signs are as expected with t-ratios exceeding 1.5 in 10 of 16 two-digit manufacturing industries. ${ }^{1}$ Indeed, in an equation for all manufacturing, the ceiling is found to have maximum effect on quits when it is roughly one half of annual earnings, which is the value predicted by Brechling's analysis of the relation between the marginal cost of a turnover and the taxable wage base.

Again, these results are suggestive. But there are no controls for individual characteristics or for the role of human capital. It would be quite interesting to carry on this type of analysis using a micro-data sample where the state is identified, and if possible where some information is given on job tenure (as in the Michigan Panel Study on . Income Dynamics

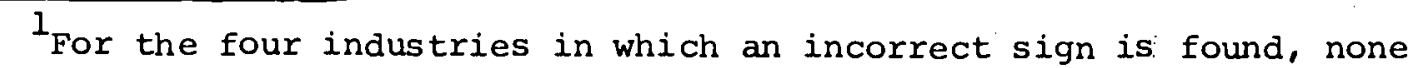
of the relevant coefficients is significant. 
or the Parnes Data).

An interesting point about the effect of the ceiling on taxable wages is that in a dynamic world with continuous turnover and replacement, this is a feature of the UI system that acts to reduce turnover---having the opposite effect on unemployment from other better known effects, such as those of UI benefits on duration.

Despite the potential effect of the ceiling on payroll subject to UI taxes, results may sometimes be unaffected if a measure of the ceiling is not included as an independent variable in a cross-section regression relating parameters of the tax system to unemployment. The reason is that during some time periods, the value for the ceiling does not vary very much among states. That is especially true if the Federal ceiling has recently been increased. ${ }^{1}$ This does not mean, however, that the effects of ceiling on turnover should be ignored in summing up the impact of the UI system on unemployment. It does mean that difficulties may be encountered in attempting to estimate its impact in cross-section studies.

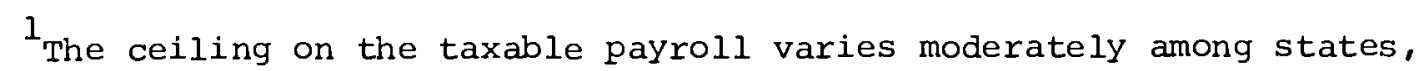
and in some years very little. For example, some interstate variation in the taxable wage is evident in the period covered by the Brechling-Jehn study (1963-1967). At the end of the 1965 eighteen states had raised the taxable wage base above the $\$ 3,000$ federal level. For most of these eighteen states the level was set at $\$ 3,600$ (Merrill G. Murray, 1966, p. 36). Ten years later only six states had tax bases exceeding the $\$ 4,200$ federal level which went into effect three years earlier (Hamermesh, 1977, p. 7). If the re has been only limited variation in the ceiling on taxable payrolls, this means that even though a study may have ignored the incentive for limiting turnover from this source, estimates of other coefficients obtained are not biased. The omitted independent variable was effectively held constant. 


\section{Interdependence Among Labor Market Flows}

Before leaving the discussion of how the UI system affects the incidence of turnover from employment for various reasons, it is appropritate to note that the incidence of temporary layoffs, permanent layoffs, other job loss and quits may be jointly rather than independently determined. Most of the studies of the impact of the UI system on these various turnover rates do not consider such interdependence in formulating and interpreting estimating equations.

Consider three reasons for the existence of interdependence in turnover rates. First, as Stephen T. Marston (1979, p. 17) notes when disucssing Feldstein's analysis of temporary layoffs: "If firms respond (as Feldstein asserts) by increasing layoffs, some workers may be less likely to quit, anticipating they will become unemployed anyway through layoffs." Furthermore, It is especially important when longitudinal data are used to consider the implications of quits from layoffs for interdependence in the determination of temporary and permanent layoffs. For in this case, temporary and permanent layoff are defined on an ex post basis. Consequently, a quit from layoff turns what would otherwise be a temporary spell of unemployment into a permanent one. A second reason why interdependence may be important is provided by the human capital literature. The analysis of specific training points to the very close relation between the decisions to lay a worker off temporarily and permanently. ${ }^{l}$ The role of the UI system in influencing such decisions has been discussed above. A third reason, namely potential

1 Gary S. Becker's (1975) book is a basis reference. 
interdependence between the quit rate and the rate of discharge for cause, is discussed by James Medoff (1979) in the context of an analysis of the impact of unions on layoffs.

An implication of such interdependence is that equations designed to estimate the impact of the UI system on each type of turnover may require a common set of explanatory variables. For example, even though the cost of temporary layoffs to the firm is not likely to be influenced by the ceiling on payroll subject to the UI tax, the relative incidence of temporary layoff may be influenced by the ceiling on taxable payroll because the relative costs of quits and permanent layoffs are influenced by the height of the ceiling.

One more aspect of interdependence among labor market flows and the potential impact of the UI system should be mentioned. The standard approach to determining whether the UI system facilitates more efficient search is to analyze the impact of UI benefits on wages subsequent to unemployment (see, for example, Ronald G. Ehrenberg and Ronald Oaxaca, 1976). Finis welch (1977) has pointed out some difficulties with such an approach. An alternative approach, consistent with our framework for analysis, is to investigate whether higher UI benefits are associated with another implied effect of a better job match---stronger attachment to the job. The better the match between a worker and a firm, the less likely a permanent separation ought to be. This means that, other things the same, if the longer duration of unemployment brought about by the availability of UI benefits is associated with more effective search and a better match, a result may be a lower rate of incidence of permanent 
layoffs or quits in states which offer higher UI replacement rates. Available studies do not provide reliable information about the effects of UI benefits on incidence of permanent turnover. For example, in the case of quits, neither the Brechling and Jehn study nor the Marston study provides an indication of whether the incidence of quits or quit unemployment is reduced in states that offer higher UI benefits. The Brechling and Jehn study includes no measure of UI benefits. Marston's measure of UI benefits is weighted by the probability it will be received by a person who quits. This is inappropriate if one is trying to isolate the effect of duration in the previous spell on the probability of a subsequent quit.

A second measure of firmer job attachment is job tenure. However, to produce a reliable analysis of the impact of UI on job tenure or permanent turnover, a more detailed modeling effort which spells out the role played by specific training and the implications of the UI system for job tenure and turnover is required.

\section{Number of Spells}

Having discussed the impact of the UI system on the incidence of a separation from past employment, consider its impact on a measure related to incidence---the number of spells per person. A technique for measuring the probability of repeated spells and attempting to isolate the role of heterogeneity---that is, individual specific characteristics leading to repeated separations and spells of unemployment---is discussed by Linda Leighton and Jacob Mincer (1979). It would be of interest to 
determine how much, if any, of the impact of the UI system is due to its effect on the likelihood of repeated spells of unemployment rather than to its impact on the probability of a random individual experiencing at least one separation. While the data are available for such an investigation, it has not been undertaken.

If we are to understand the relation of UI to unemployment associated with repeated spells, the following questions should be investigated: ${ }^{1}$

- Do UI benefits and taxes affect the likelihood of individuals experiencing repeated spells of unemployment? Of repeated spells resulting in permanent separation?

- What portion of the probability of repeated spells and of total time spent unemployed is due to individual differences in preference or individual characteristics (heterogeneity) and what part is due to the fact that a person with short tenure on the current job has a greater likelihood of turnover? How does UI influence this outcome?

E. The Impact of UI on the Probability of Unemployment Conditional on a Turnover, $z_{i}^{\prime}$

There has been no separate study of the relation of parameters of the UI system to the probability of unemployment conditional on a turnover.

$1_{\text {Heterogeneity may affect duration as well as incidence of unemploy- }}$ ment. More specifically, heterogeneity may lead to adverse selection as those with a strong preference for leisure time choose jobs where permanent separation is more likely and then prolong their spells. Additional questions for future investigation are:

- Does duration differ for those experiencing repeated spells? Is the impact of UI on duration different for those experiencing repeated spells? 
One might expect that in the case of a temporary layoff there is little room for the UI system to affect the value of such a probability. On the other hand, it may be argued that the propensity to locate a job before quitting and thus avoid experiencing unemployment varies negatively with the expected value of UI benefits to those who quit. But, as noted, Marston's (1979) findings do not support this argument. It might be expected that UI benefits affect the probability of unemployment by influencing the probability of an unemployed person--either on temporary layoff or permanently separated---taking a temporary position, perhaps on a part-time basis. This effect should depend on both the relative level of UI benefits and the way these benefits are reduced in the face of part-time work. Raymond Munts (1970) presents evidence that work activity is influenced by rules governing the payment of partial benefits.

F. The Impact of the UI System on the Stocks of Those Employed and Not In the Labor Force: $S_{i}^{\prime}$

If the UI system affects transition rates into and out of employment and thereby the stock of unemployed, it also affects the stocks of the employed and those not in labor force. There are at least three reasons why, as part of our analysis of the impact of UI on unemployment, we should be interested in determining the effects of the UI system on. the number employed and not in the labor force. First, as demonstrated in Section I, a portion of the effect of the UI system on unemployment results from its impact on these stocks. Accordingly, to determine the 
full impact of UI on unemployment, its impact on the number employed or not in the labor force must be understood. ${ }^{1}$

Second, it is important to determine whether any increases -- or, in certain instances, decreases -- in the number of unemployed attributable to the UI system come from its effect on employment or the number not in the labor force. Most crucially, we would like to know whether any addition to the stock of unemployed represents a real effect of a reporting effect. It is a real effect if those who would have been employed in the absence of UI choose unemployment because of its availability. It is a reporting effect if, for example, some put off exit from the labor force in order to remain qualified for UI benefits.

Third, the fact that certain aspects of the UI system may affect the stocks of those employed or not in the labor force provides further opportunity to test for the empirical importance of effects suggested by various theories.

Three recent studies which consider the effects of the UI system on employment and/or not in labor force time will be mentioned. One is a study of seasonal employment patterns by Terrance C. Halpin (1979). The second is a study by Daniel Hamermesh (1979a) which examines UI induced effects on labor force participation that, in turn, are reflected in employment. Hamermesh's is a supply side study of behavior in the short term and is based on data for married women. The third is a study

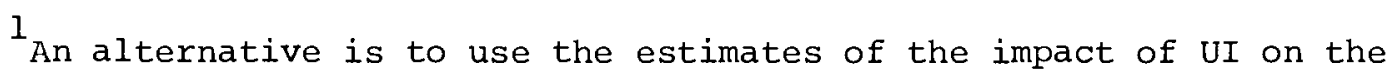
nine transition rates among the three states of unemployment, employment and not in the labor force to produce an estimate of the full impact of UI on unemployment. For a discussion of the appropriate formulae, see Stephen T. Marston (1976) and Ronald G. Eherenberg (1979). 
by Gary Solon (1979) concerning the effects of extended benefits on unemployment, employment and not in labor force status for a sample of the long term unemployed.

There are two important innovations in Halpin's study. First, he includes as an independent variable a measure designed to capture seasonal shifts in the demand curve (weather conditions by state). The presence of a direct measure of the position of the demand curve acts to reduce specification error in a study such as his which draws on demand side behavior. Second, he makes an effort to measure directly the degree of experience rating. He finds that for two of three industries examined, more perfect experience rating is associated with reduced seasonal employment fluctuations. ${ }^{1}$

Two effects are considered in Hamermesh's study. On the one hand, women who work and earn beyond a threshold level this period are entitled to receive UI benefits next period, if they become unemployed for acceptable reasons next period. Moreover, once having qualified for the minimum, higher earnings raise benefits, at least up to the maximum. The fact that working in the current period increases potential benefits in future periods provides an added incentive to work. ${ }^{2}$ The more generous the UI benefits, the stronger the "entitlement effect" should be. On the other hand, once a person has qualified for UI benefits,

$l_{\text {The dependent variable is a measure based on spectral analysis of }}$ the seasonal patterns in employment.

2 Unless, of course, there is a fully compensating wage differential. 
since higher benefits lower the price of unemployment relative to employment, higher benefits may discourage work effort. Using data from the Panel Study on Income Dynamics, Hamermesh finds evidence for both of these effects, but finds they are largely offsetting.

Using a survey of people who had exhausted their regular UI benefits, but who were not equally qualified to receive extended benefits, Gary Solon found, for a sample of workers in New York State, that those who were eligible for extended UI benefits were unemployed for a longer time, and that, other things the same, they spent less time employed or not in the labor force. Eligibility for extended benefits caused a different response for those who had been unemployed in at least two of the last five years than for those who had not. The "repeaters" were more likely to reduce employment time, spending more time unemployed if they were eligible for extended benefits. Nonrepeaters spent more time unemployed at the expense of time that would have been spent out of the labor force. There is some question about these results because solon indicates there was a high correlation between the labor market conditions a worker faced and eligibility for extended benefits. Nevertheless, the questions asked are quite important and should be investigated in a cross-section setting for a more representatime sample of the unemployed. 
G. Impact of UI on Unemployment Duration: $d_{i}^{\prime}$

There has been a great deal of work, both theoretical and empirical, attempting to explain how and why the UI system affects unemployment duration. The empirical work, which has applied a variety of econometric techniques to analyze data from a number of different sources, suggests, consistent with the bulk of the theory, that higher UI benefits are associated with longer spells of unemployment. ${ }^{1}$ Indeed, it is fair to say that the positive relationship between weekly benefits and duration is the most reliable result we have on the impact of the UI system. Despite this, it should be recognized that we do not have enough information to fill in the bottom row of the table in Figure 1, thereby indicating the effects of the various features of the UI system on duration of unemployment for those experiencing unemployment for different reasons. Usually, an "average" duration is calculated for a group which includes individuals unemployed for a number of different reasons. The group may include all the unemployed or all the insured unemployed, all job changers or insured job changes. 2

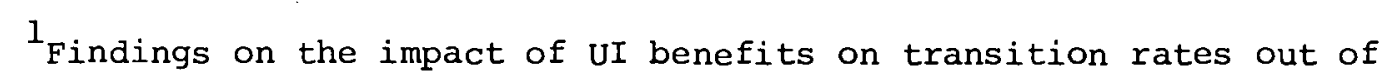
unemployment are not as extensive as those on duration. Normally, studies of UI's impact on transition rates focus on the effects of UI coverage, but not on the impact of variation in benefit levels. (E.g., see John M. Barron and Wesley Mellow, 1979.). Since UI coverage is endogenous, care is required in interpreting these findings. The related problem in duration studies is selection into samples of covered workers.

2 There are some exceptions. E.g., as will be mentioned below, Kathleen P. Classen's (1979) study analyzes the determinants of duration separately for those insured unemployed who are on recall layoff. But most studies do not separate the unemployed by reason for unemployment before analyzing UI's impact on duration. 
Since, as Feldstein (1975) (1978) has noted, duration varies by reason for unemployment, if benefit replacement rates do not have the same effect on the incidence of unemployment for different reasons, variation of average duration of an unemployment spell will reflect the influence of two forces--the impact of variation in parameters of the UI system on duration and its impact on the mix of unemployed by reason for unemployment. Suppose, for example, that the equation for estimating duration is of the form:

$$
\mathrm{d}=\mathrm{f}(\mathrm{UIB}, \mathrm{CD}, \mathrm{W}, \mathrm{X})
$$

where $d$ is the duration of unemployment, UIB is some measure of benefits, $\mathrm{CD}$ is the period of covered duration, $\mathrm{W}$ is the past wage and $\mathrm{X}$ is a set of supply side demographic and human capital characteristics. From Equation 6, Section I, we have

$$
\mathrm{U}=\mu \cdot \mathrm{d} \text {. }
$$

That is, unemployment is equal to the product of average incidence ( $\mu$ ) and duration of completed spells (d). Noting from Equations 6 and 7 that

$$
U=\sum_{i} \mu_{i} d_{i}
$$

and using Equation 1, 


$$
d=\frac{\sum \mu d_{i}}{\sum \mu_{i}}
$$

or

$$
d^{\prime}=\frac{\sum_{i}\left(\mu_{i} d_{i}^{\prime}+d_{i} \mu_{i}^{\prime}\right)}{\left(\sum \mu_{i}\right)}-\frac{\sum_{i} \mu_{i} d_{i} \sum_{i} \mu_{i}^{\prime}}{\left(\sum \mu_{i}\right)^{2}}
$$

That is, since average duration is equal to the sum of the products of incidence and duration by reason for unemployment divided by total incidence, d' depends not only on the effects of variation in benefits on duration by reason for unemployment (each of the $d_{i}^{\prime}$ ), but also on the level of incidence by reason and variation in incidence by reason resulting from variation in benefits.

Having noted that the dependent variables used in most duration studies measure duration for an aggregated group of those who are unemployed for different reasons, and also having noted the consequences of this fact, consider now the information that is available on the impact of UI on duration for groups unemployed for different reasons.

Duration of Temporary Layoff Unemployment, $d_{1}^{\prime}$

The theory relating the UI system to the duration of temporary layoff unemployment is an extension of that in the Baily-Feldstein models. Just as the UI subsidy (imperfect experience rating and the tax break) may encourage the incidence of temporary layoff unemployment, a higher subsidy may lead to the prolongation of spells. Whether duration is 
increased where the subsidy is higher depends on the impact of the subsidy on the relative incidence of shorter spells.

Findings from two studies will be noted. Classen (1979) calculated the impact of UI benefits separately for those recalled by their initial employers. The UI parameters in her estimating equation referred only to the benefit formulae. Administrative data from Pennsylvania and Arizona were used as a basis for analysis. The coefficient estimated for the benefit measure is two to three times smaller in the equations estimated for those recalled by their previous employers than in the equations for those not recalled.

Frank Brechling (1979) has tried to test an extension of the FeldsteinBaily model by including tax parameters as explanatory variables in a duration equation. His observations are by state and by year. However, the dependent variable used is average duration of unemployment by state computed for the entire group of unemployed in the state, whatever the reason for their unemployment. Moreover, none of the exogenous measures included by Feldstein (1978) in his analysis are standardized for by Brechling in his. As a result, it would seem most prudent to view this study (as does Brechling) as a first, rough attempt at analyzing the impact of the tax side of the UI system on duration of temporary layoff unemployment. Brechling finds that the parameters of the UI tax system have a systematic relation in the expected direction to overall duration. Less perfect experience rating is associated with longer spells. With tax variables in the equation, the benefit measure does not have a significant impact, although the sign on the benefit variable is positive. 
Duration of Unemployment for Permanent Layoffs, Other Job Losers and

Job Leavers, $d_{2}^{\prime}, d_{3}^{\prime}, d_{4}^{\prime}$

As noted in the beginning of this section, separate findings are

not available for the impact of UI on duration for those who were

permanently laid off, lost their job for other reasons or quit. (Moreover,

those on temporary layoff are often included in the same sample-vith these others.) $)^{l}$

Accordingly, this part of the discussion of the impact of UI on duration,

by necessity, is based on results for these groups taken together.

The features of the UI system of greatest importance to these

analyses are the benefit level or replacement rate and the potential

duration of benefits. Job search requirements and eligibility rules

may be important, but their effects are not normally standardized for

in available studies. (See, however, the studies by Arlene Holen and

Stanley Horowitz, 1974, and Stanley Horowitz, 1977).)

To avoid needless duplication with previous surveys which have

covered both the relevant theory and empirical work explaining the impact

of the benefit replacement rate on unemployment duration, let me cite

conclusions from two of the major surveys of this literature and then

go on to discuss the impact of potential duration on actual duration. ${ }^{2}$

Based on his survey, Hamermesh (1977) concludes "that a 10-percentage

point increase in the gross replacement rate leads to an increase in the

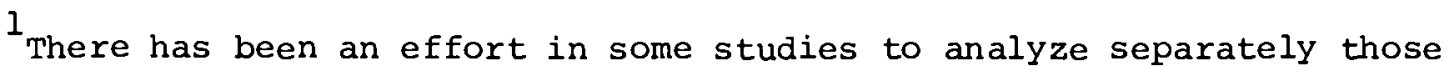
who are unemployed for different reasons. For example, in addition to Classen's study, Ronald G. Ehrenberg and Ronald Oaxaca (1976) separate out from their samples those on temporary layoff. Also, there is the work of Henry E. Felder (1978) on duration and disqualifications which is discussed below. Finally, in their study of differences in transition probabilities out of unemployment associated with UI coverage, Barron and Mellow (1979a) include as independent variables a set of dummies to indicate the reason for unemployment.

2 For anoverview of recent developments in the theory, see steven $A$. Lippman and John J. McCall (1979). 
duration of insured unemployment of about half a week when labor markets are tight" (p. 37). Topel and Welch's best guess is that a..I increase in the benefit replacement ratio extends the average unemployment spell by 1.2 weeks for job changers. (p. 84).

Some of the studies covered in these surveys were based on program data from state UI systems. Dependent variables in these studies are truncated because the length of the recorded spell is limited by maximum weeks of compensated unemployment, so that unemployment beyond the time when benefits are exhausted or before the time when potential recipients register for benefits is not recorded. More recent studies, such as those by Floyd C. Newton and Harvey Rosen (1979) and Classen (1979), employ maximum likelihood techniques to deal with truncation, at least on the far end of the spell. Their findings are consistent with those of earlier studies.

Turn now to consider the impact of potential duration of UI benefits on actual duration of unemployment. Findings as to the impact of maximum potential duration are mixed. ${ }^{1}$ One problem is that program data may not provide much variation in maximum potential duration because many observed individuals are at the maximum, especially in states where those who are eligible for benefits at all are made eligible for the maximum duration allowable. Another is that the required estimating

$1_{\text {For example, Ehrenberg, and Oaxaca (1976) find no significant }}$ impact of potential duration, Newton and Rosen (1979) find there is one and Classen (1979) finds a significant impact in one of two states examined. 
procedure is quite complicated because the UI budget constraint changes slope at the point where UI benefits run out. Thus the opportunity cost of unemployment is increased to the full foregone wage for weeks beyond the maximum. As a result, the opportunity cost relevant to an individual's marginal decision is endogenous.

In one of the most technically sophisticated of the studies of this subject, Robert Moffitt and Walter Nicholson (1979) focus on the impact of Federal Supplemental Benefits (FSB) on duration. By extending potential duration by 26 weeks, this program created wide variation in potential duration during a time of cyclical downturn. They concluded that "an increase of one week in potential duration resulted in a. I week increase in weeks unemployed. . the entire FSB program resulted in increasing weeks unemployed by about 2.5 weeks." (pp. 34-35)

A third feature of the UI benefit structure is the disqualification provisions. Henry E. Felder (1978) has used program data to compare the differences in duration between those disqualified from receiving UI benefits for various reasons on the one hand and all qualified recipients on the other. His results suggest that those permanently disqualified from receiving benefits during a given spell because they quit their last job are unemployed for a shorter period of time than are those who are qualified for benefits. Since the group who are qualified includes those on temporary layoff and the duration of their unemployment is short, the difference brought about by permanent disqualification may be somewhat understated. Felder also finds that those who quit and are disqualified for a waiting period, but not for 
the full duration of the spell; have longer spells than qualified recipients, as do those who are disqualified for declining suitable work. The results for those discharged for misconduct vary among states. Separate duration equations are not presented for those who quit, were discharged for cause, etc.

New Entrants $d_{5}^{\prime}$

It has also been argued that duration of unemployment for new entrants may be affected by the UI system. One reason may be that the sooner a job is accepted, the sooner one is eligible for potential future benefits (Hamermesh, 1977, p. 37).

on apriori grounds one would not expect this type of effect to play a major role in influencing duration of entry level unemployment; but there is no evidence either way.

\section{Future Research on Duration}

What are the questions that need to be answered if the effects of the UI system on duration are to be pinned down more precisely? First, more disaggregation is called for so that the differential effects of the UI system on duration by reason for unemployment can be understood. Second, it is important to determine the size of errors which have been introduced because the measures representing benefits or taxes are endogenous to the analysis. This is most obvious when actual benefit replacement rates, or measures such as the fraction of benefits paid to employees of firms paying the maximum tax are used. But even parameters of a state's benefit and tax system may be endogenous, especially in view of the fact that over the long term, benefit and tax payments must 
balance at the state level. ${ }^{1}$ one would expect that the greater the degree of aggregation, and thus the less important the role of differences among individuals or firms in determining the error term, the more serious these simultaneous equations problems will be.

Third, if we are to zero in on the effects of the UI system on duration, we need a careful effort to catalogue the differences in findings that are associated with using different data sets, or more broadly, different definitions of labor market flows. There are at least four major categories of surveys used to test theories of the relation of unemployment insurance to unemployment -- CPS type surveys, the BLS employer surveys (observations by state, industry and year), longitudinal surveys, such as the parnes data and Michigan's Panel study of Income Dynamics, and surveys based on program data which include only those who are in employment covered by the UI system or are receiving UI benefits. Different surveys define differently some of the unemployment related flows. (Martin S. Feldstein [1975] discusses some of these differences.)

The CPS measures current unemployment and duration of incomplete spells for the five subgroups of the unemployed noted in Figure 1 . Further information can be gained either by matching panels from the CPS and calculating flows as changes in status between survey periods (Clark and summers, 1979, Barron and Mellow 1979), or by calculating escape rates from the information on duration of incomplete spelis of unemployment and using them to estimate the duration of completed spells.

The longitudinal surveys are used to provide information on the incidence and duration of completed spells. However, even though

${ }^{l}$ Note also that if the legislature takes local economic circumstances into account in designing the UI system, this may cause the parameters of that system to be endogenous in many analyses. See Hamermesh (1978b) for some discussion of this issue. 
longitudinal surveys provide information about status during the week of the survey, in an effort to take advantage of the unique characteristics of these surveys, temporary layoff is normally defined in an expost rather than exante sense as in the CPS (e.g., see Leighton and Mincer, 1979, and Ehrenberg and Oaxaca, 1976). Thus, for example, those that quit from temporary layoff unemployment and secure a job for a new employer are counted in these surveys as permanent layoffs. Program data utilize similar definitions, but as noted above the sample covered by program data is censored and appropriate adjustments are required. In addition, different data sets incorporate different measures of exogenous influences. A systematic attempt should be made to catalogue the effects of including or excluding particular subsets of exogeneous variables to reveal how much of the differences among studies reflect differences in specification of the estimating equation.

Fourth, although studies of duration are based on longitudinal data, they normally do not distinguish between effects of the UI system on the behavior of those who frequently experience spells of unemployment as compared to those who do not. If we are to isolate parameters that truely reflect the impact of the UI program on an individuals' behavior, it is important to standardize for the effects of the heterogeneity (e.g., see Solon (1979)).

Fifth, it may be useful to distinguish spells that end out of the labor force from those that end in a new job. We are just beginning to consider this distinction in analyzing the impact of unemployment insurance. 
III. Summary and Implications for Further Research

In the first part of this paper, a framework for viewing developments in the literature analyzing the relation of unemployment insurance to unemployment was constructed. That framework provided an outline for section II, which contained a discussion of recent developments in that literature. In the process of discussing the literature, an effort was made to point to important questions which, if answered, would lead to a more complete understanding of how the UI system affects unemployment.

This concluding section will attempt to summarize briefly some major points raised in the discussion and to highlight some of the broader questions for future research that are suggested by the foregoing review. The more specific questions that arose during the course of discussing particular developments in the literature will not, however, be repeated.

\section{Temporary Layoff unemployment}

Consider first the available information concerning the relation of the UI system to temporary layoff unemployment. The basic theoretical work has been carried out by Baily (1977) and Feldstein (1976). There is one major empirical study (Feldstein, 1978) focussing directly on the impact of UI on the level of temporary layoff unemployment. In addition, Brechling (1976) has pointed out how parameters of the UI tax system might be incorporated into this framework. 
Less information is available on the effect of the UI system on the probabilities which underlie the level of temporary layoff unemployment. Brechling's work on the incidence of temporary layoff is very rough. There is no empirical work analyzing the relation of UI to the conditional probability of unemployment given a temporary layoff (although this probability may be high and not very much affected by UI). Moreover, of the two studies focusing on UI's impact on duration of temporary layoff unemployment, one (Classen, 1978) focuses only on a supply side explanation, and the other [Brechling (1979)] is.based on highly aggregated data.

The information we have on the impact of the UI system on the incidence and duration of temporary layoff unemployment confirms the direction of Feldstein's findings. But the size of the effect found in his study is very large. In view of the importance of this effect, and since his study did not control for interstate differences in the degree of experience rating, an important priority for future research is to attempt to confirm or refute Feldstein's findings, while incorporating innovations suggested by Brechling.

Permanent Layoff Unemployment

The review of findings on the impact of UI on permanent layoff unemployment has indicated that these results are incomplete. Only limited work on the relation of UI to the incidence of permanent layoff unemployment has been carried out. That work, which is mainly due to Brechling and Jehn (1978), analyzes the impact of UI on the incidence of 
total layoffs and recalls. Direct evidence concerning the size of the impact of the UI system on the incidence of permanent layoffs or on unemployment conditional on permanent layoffs is not available. Moreover, while duration studies confirm that the impact of UI benefits is in the expected direction, most of the duration studies do not separate individuals by reason for unemployment. Additional work aimed at spelling out the structual relations underlying the incidence of permanent layoffs by merging supply and demand based models, and providing estimates of UI's impact on duration for those on permanent layoff, could help us to zero in on a point estimate of the effects of the UI system on permanent layoff unemployment.

Other Job Loss, Quits and Entry

Similar comments to the above apply to the information that is required if we are to come closer to having point estimates of the impact of the UI system on unemployment associated with other job loss or quits. Some work on the supply side is available relating UI benefits to the incidence of quit unemployment. But there is none on the relation of the UI to the incidence of unemployment from other job loss, to the probability components of unemployment due to other job loss, or to entry unemployment.

\section{Gaps In the Theory and Implications for Estimation}

A few more general comments about gaps in the theory are in order. It has been apparent throughout the discussion that more work is needed analyzing the relations between the UI system and specific training on the one hand and layoff policies of the firms or corresponding supply 
side incentives to quit on the other. Relatedly, we have no information on the positive aspects of the impact of the UI system on unemployment i.e., or any reduction in the incidence of unemployment over the long term and, perhaps, increases in job tenure due to improved job matches resulting from prolonged search financed by UI benefits.

In addition, it would be useful if theoretical analyses of the relation of UI to unemployment incidence placed more emphasis on the roles of risk and uncertainty, and if they considered more fully the implications of heterogeneous preferences.

\section{The UI System}

The effects of two features of the UI system deserve closer study. The feature are the ceiling on taxable wages and the procedures for determining eligibility and qualification for UI benefits. It is particularly important to isolate the impact of the ceiling and to determine how important it is because it may operate systematically to reduce turnover with replacement, and thus in contrast with many of UI's effects, to reduce unemployment. The impact of the maximum taxable salary on turnover rates has been examined using aggregated data for manufacturing by Brechling and Jehn (1978), but more detailed work is called for using micro data. This work will be difficult to accomplish because, at times, the interstate variation in the maximum yearly wage subject to UI tax is limited. .

To summarize the findings, when one proceeds systematically through the analytical framework presented in section I and compares it to the topics considered in the available literature, a guide to future research emerges. We have seen that certain labor market flows which determine in part the number who are unemployed, and which may be influenced by 
the characteristics of the UI system, have not been studied. Other relevant labor market flows have been studied, but only partially. In addition, some aspects of the behavior of individuals and firms which may be altered in response to incentives provided by the UI system have not yet been considered. And the impact of certain features of the UI system has yet to be fully analyzed.

It has also been seen that if results from various empirical studies are to be reconciled, an effort has to made to put together on a systematic basis information indicating how differences in the data employed, econometric techniques used and specification of estimating equations affect empirical findings.

This paper has drawn on a large body of information pertaining to the impact of the unemployment insurance system on unemployment. It is obvious that significant progress has been made, and that much of the information that has been accumulated can be very useful to those responsible for designing the UI program. This information is especially useful when it is viewed within the context of an appropriate analytical framework. Yet, when viewed in this context, it is also apparent that a great deal of work remains to be done. 


\section{Appendix}

Worker Heterogeneity and Adverse Selection: An Example

The role of moral hazard provides one explanation for the observed positive relation between the level of UI benefits and unemployment duration (see for example Steven Shavell and Laurence Weiss, 1979). This appendix provides an example in which workers with the strongest preference for nonmarket time may select those occupations where permanent separation occurs most frequently, taking advantage of the availability of UI benefits to further increase their yearly unemployment. While in this example there is full coverage, so availability of UI benefits does not influence the choice of industry by workers, it is seen that because those who have the strongest preference for nonmarket time will choose to work in industries where unemployment is most likely, the effect of such occupational choice is to magnify the impact of moral hazard. This adverse selection is seen to operate in that workers with a strong preference for nonmarket time choose industries where unemployment, rather than UI coverage, is more likely.

To highlight the mechanism and to simplify the example, it will be assumed that there is no uncertainty about demand fluctuations and that workers have full information about employment prospects, so there is no need for search. It will also be assumed that the UI system is fuily experience rated. The imperfection which accounts for the effect of UI on duration is an assumed inability of firms to determine which workers have a strong preference for time away from the job. ${ }^{1}$

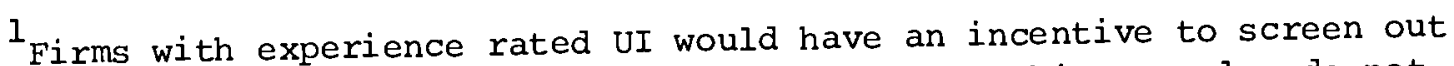
such workers, or to offer them a lower wage, but in this example, do not do so successfully. 
To be more specific, assume there are two industries, $A$ and $B$, and workers in both industries are covered by unemployment insurance. Further assume that it is known with certainty that in $A$ there will be no unemployment, while in B there will be a layoff for one of $n$ periods. 1 The layoff is treated as permanent, although in the period following the layoff anyone who wants to work can find a job at one firm or another in the industry. Instead of returning to work after one period, however, employees are assumed to have the option of extending the spell of unemployment for another period, while remaining covered by unemployment insurance. This option corresponds to the possibility that unemployment may be voluntarily prolonged even though the search required to qualify for UI benefits is "formally" met by the unemployed worker. Yearly earnings and the per period wage rate are reported in Panel I of Table 1 for the dominant group of workers, who, for purposes of example, are assumed to place a zero value on any nonmarket time arising from layoff. This group, through its mobility and dominance of employment, determines what the wage structure will be. Another smaller group exhibits a positive preference for nonmarket activities. They allocate themselves among industries in light of this wage structure and employment prospects, choosing that industry which offers the most attractive combination of earnings, UI benefits and leisure time. Finally, for convenience, assume that industry $A$, the industry for which there is no possibility of unemployment is very large. As a result, it is possible to ignore any adjustments in the yearly wage paid in that industry as

\footnotetext{
${ }^{1}$ Once laid off, it takes one period to locate a job in any industry.
} 
Table 1

Panel I: Value of Layoff Time $=0$

\begin{tabular}{|c|c|c|c|}
\hline & $\begin{array}{c}\text { Yearly } \\
\text { Earnings }\end{array}$ & $\begin{array}{c}\text { Per Period } \\
\text { Earnings }\end{array}$ & $\begin{array}{c}\text { Total Value of Choice } \\
\text { (Earnings }+ \text { UI }+ \\
\text { Leisure) }\end{array}$ \\
\hline No Unemployment & (A) $w_{0}$ & $\frac{\mathrm{w}_{\mathrm{O}}}{\mathrm{n}}$ & $w_{0}$ \\
\hline Unemployment & (B) $\frac{w_{0}(n-1)}{(n-1)+\infty}$ & $\frac{\mathrm{w}_{0}}{(\mathrm{n}-1)+\alpha}$ & $w_{0}$ \\
\hline
\end{tabular}

Panel II: Positive Value of Layoff Time

\begin{tabular}{|l|c|c|c|}
\hline No Unemployment & (A) $w_{0}$ & $\frac{w_{0}}{n}$ & $w_{0}$ \\
\hline $\begin{array}{l}\text { Unemployment } \\
u=1\end{array}$ & (B) $\frac{w_{0}(n-1)}{(n-1)+\propto}$ & $\frac{w_{0}}{(n-1)+\propto}$ & $w_{0}+\beta(1)$ \\
\hline$u=2$ & (B) $\frac{w_{0}(n-2)}{(n-1)+\propto}$ & $\frac{w_{0}}{(n-1)+\propto}$ & $\frac{w_{0}[(n-2)+2 \propto]}{(n-1)+\propto}+\beta(2)$ \\
\hline
\end{tabular}


labor shifts into B. A full analysis must, of course, relax each of these simplifying assumptions.

The following notation is used:

$w_{0}=\begin{aligned} & \text { Yearly earnings in industry } A, \text { the dominant industry with } \\ & \text { no unemployment }\end{aligned}$
$n=$ Number of periods per year
$\alpha \quad=$ Proportionate rate of replacement for earnings by UI
$\beta(t)=\begin{aligned} & \text { Value associated with } t \text { periods unemployment for those } \\ & \text { with a positive preference for nonmarket time. }\end{aligned}$

It can be seen from Panel I that for those who attach no value to nonmarket time, labor mobility causes wage rate adjustments which equalize the total returns to working in each industry at $w_{0}$ (Column 3 ). This is so whatever the level of UI benefits or average unemployment experience. Moreover, as long as $\alpha$, the replacement rate for UI, is less than one, with $\beta(t)=0$ for Group I no one who works in industry B will choose to exercise an option to take an extra period of unemployment. (It is easy to derive analogous conditions under the assumption that for the majority group $B(t)>0$, but is less than the value of leisure for the minority group.) Panel II examines the case for that smaller group of workers for whom there is a positive value to time spent not at work--i.e., for whom $\beta(t)>0$. There are few enough of them so that the wage rate structure they face is independent of their behavior. Their yearly earnings are obtained by multiplying the wage rate by $\mathrm{n}$ or $\mathrm{n}-1$ periods, depending on whether there is mandatory unemployment associated with their industry. The calculation in the last row is made to illustrate the value of choosing 
a second period of unemployment. The total value of each choice is equal to the value of earnings plus the UI payment replacing wages at the rate of $\propto$ times the number of periods unemployed, plus the value of nonmarket time. From these results, conditions under which those with a preference for nonmarket time will choose to lengthen their unemployment after choosing to work where unemployment is expected with certainty can be determined.

Note that since wages reflect the preferences of Group I so that monetary returns are equal in both industries, those in Group II with a preference for nonmarket time will sort themselves into industry $B$. The value of total returns there is higher for them than it is in $\mathrm{A}$, where there is no unemployment. The difference is equal to the value they place on nonmarket time. A central question is under what conditions will those in Group II choose to lengthen their unemployment voluntarily beyond the mandatory period length, and if they do, what role will unemployment insurance play? The condition for staying unemployed two periods rather than one is that

$$
\frac{w_{0}[(n-2)+2 \propto]}{(n-1)+\propto}+\beta(2)>w_{0}+\beta(1)
$$

or

$$
\left(\beta_{2}-\beta_{1}\right)>w_{0} \frac{(1-\alpha)}{(n-1)+\alpha}
$$

More simply, the worker with a positive preference for nonmarket time will choose an extra period of unemployment if time away from the job is valued 
at more than foregone earnings not covered by UI benefits.

In sum, this example points out that if labor allocates itself among jobs in such a way that those with the strongest preference for unemployment are concentrated where permanent separation is most likely to occur, the potential for UI benefits to have an adverse impact on duration is increased. ${ }^{1}$ Most studies of duration, however, have not tested for and do not control for the influence of heterogeneity of worker preferences.

$1_{A}$ related point is made by Gary Solon (1979) with regard to the effect of UI on labor force participation. He points out, that if UI encourages participation, it does so for those most prone to long spells of unemployment. Solon is careful to note, however, that by increasing participation by those with a weak preference for work, UI is not creating a disincentive for work. In contrast, UI does create such a disincentive in the above example. 
$\underline{\text { References }}$

Abowd, John and Ashenfelter, Orley. "Unemployment and Compensating Wage Differentials," mimeo, 1979.

Baily, Martin Neil. "On the Theory of Layoffs and Unemployment," Econometrica, July 1977a, 45(5), pp. 1043-1063.

- "Unemployment Insurance as Insurance for Workers," Industrial and Labor Relations Review, July 1977b, 30(4), pp. 495-504.

Barron, John M., and Mellow, Wesley. "Unemployment Insurance: The Recipients and Its Impact," mimeo, 1979.

- "Search Effort in the Labor Market," Journal of Human Resources, Spring 1980, 14(3), pp. 389-404.

Becker, Gary S. Human Capital, second edition. New York: Columbia University Press, 1975.

Becker, Joseph M. Experience Rating in Unemployment Insurance. Baltimore: Johns Hopkins University Press, 1972.

Brechling, Frank. "The Incentive Effects of the U.S. Unemployment Insurance Tax," in Ronald Ehrenberg (ed.), Research in Labor Economics, I, Greenwich, Conn.: JAI Press, $197 \overline{7 .}$

- "Layoffs and Unemployment Insurance," Arlington, Virginia:

Center for Naval Analyses, February, 1979.

Brechling, Frank, and Jehn, Christopher. "The Unemployment Insurance Tax and Labor Turnover: An Empirical Analysis," Technlcal Analysis Paper No. 56. U.S. Department of Labor, ASPER, October 1978.

Brown, Eleanor. "Experience Rating for Unemployment Insurance Taxes," mimeo, Princeton, December 1979.

Burdett, Kenneth, and Hool, Bryce. "Temporary Layoffs and the Unemployment Insurance System," mimeo, University of Wisconsin, February 1979.

Clark, Kim B., and Summers, Lawrence H. "Labor Market Dynamics and Unemployment: A Reconsideration," Brookings Papers on Economic Activity, I, 1979, pp. 13-60.

Classen, Kathleen P. "Unemployment Insurance and Job Search," in Steven A. Lippman and John J. McCall (eds.), Studies in the Theory of Search. Amsterdam: North Holland, 1979.

Ehrenberg, Ronald G. "The Demographic Structure of Unemployment Rates and Labor Market Transition Probabilities," A Report to the National Commission on Manpower Policy, July 1979. 
Ehrenberg, Ronald G., Hutchens, Robert, and Smith, Robert. "The Distribution of Unemployment Insurance Benefits and Costs," U.S. Department of Labor, ASPER Technical Analysis Paper No. 58, October 1978.

Ehrenberg, Ronald G., and Oaxaca, Ronald. "Unemployment Insurance: Duration of Unemployment and Subsequent Wage Gain," American Economic Review, December 1976, 66(5), pp. 754-766.

Felder, Henry E. "A Statistical Evaluation of the Impact of Disqualification Provisions of State Unemployment Insurance Laws," Report to the Department of Labor, Stanford Research Institute, February 1979.

Feldstein, Martin S. "The Effect of Unemployment Insurance on Temporary Layoff Unemployment," American Economic Review, 68(5), December 1978, pp. 834-846.

- "The Importance of Temporary Layoffs: An Empirical Analysis," Brookings Papers, 3, Washington, 1975, pp. 725-745.

- "Lowering the Permanent Rate of Unemployment," Study for the Joint Economic Committee, 93d Congress, 1973.

- "Temporary Layoffs in the Theory of Unemployment," Journal of Political Economy, 84(5) October 1976, pp. 937-957.

- "Unemployment Compensation: Adverse Incentives and Distributional Anomalies," National Tax Journal, 37 (2), June 1974, pp. 231-44.

Fields, Gary. "The Direct Labor Market Effects of the U.S. Unemployment Insurance System: A Review of Recent Evidence," Industrial Relations, February, 1977, 16(1), pp. 1-14.

Frank, Robert H. "How Long Is a Spell of Unemployment?" Econometrica, March, 1978, 46(2), pp. 285-302.

Hall, Robert E. "The Nature and Measurement of Unemployment," National Bureau of Economic Research, Working Paper 252, July 1978.

Halpin, Terrence C. "The Effect of Unemployment Insurance on Seasonal Fluctuations in Employment," Industrial and Labor Relations Review, April 1979, 32(3), pp. 353-362.

Hamermesh, Daniel S. "Entitlement Effects, Unemployment Insurance, and Employment Decisions," Economic Inquiry, July 1979a, 17(3), pp. 317-322. - Jabless Pay and the Economy. Baltimore: Johns Hopkins University Press, 1977. 
Hamermesh, Daniel S. "Social Insurance and Consumption--An Empirical Inquiry," mimeo, June 1979b.

. "Unemployment Insurance and the Older American," W. E. UpJohn Institute, mimeo, February 1980.

- "Unemployment Insurance and Unemployment in the United States," in Herbert G. Grubel and Michael A. Walker, Unemployment Insurance, Global Evidence of Its Effects on Unemployment. Vancouver, 1978b.

- "Unemployment Insurance, Short Time Compensation and the Workweek," Special Report No. 28, National Commission for Manpower Policy, October 1978a.

Holen, Arlene, and Horowitz, Stanley. "The Effect of Unemployment Insurance and Eligibility Enforcement on Unemployment," Journal of Law and Economics, October 1974, 17(2) pp. 404-432.

Horowitz, Stanley. "A Model of Unemployment Insurance and the Work Test," Industrial and Labor Relations Review, July 1977, 30(4), pp. 462-466.

Hutchens, Robert M. "Determinants of Labor Supply to Unstable Unemployments," mimeo, Ithaca, October 1979.

Kaitz, Hyman w. "Analyzing the Length of Spells of Unemployment," Monthly Labor Review, November 1970, 93(11), pp. 11-20.

Kiefer, Nicholas M., and Neumann, George R. "An Empirical Job-Search Model, with a Test of the Constant Reservation-Wage Hypothesis," Journal of Political Economy, February 1979, 87(1), pp. 89-108.

Lancaster, Tony. "Econometric Methods for the Duration of Unemployment," Econometrica, July' 1979, 47(4), pp. 939-956.

Leighton, Linda, and Mincer, Jacob. "Labor Turnover and Youth Unemployment," National Bureau of Economic Research, Working Paper No. 378, August 1979.

Lippman, Steven A., and McCall, John J. (eds.). Studies in the Theory of Search. Amsterdam: North Holland, 1979.

Marston, Stephen T. "Employment Instability and High Unemployment Rates," Brookings Papers on Economic Activity, 1, 1976, pp. 169-203.

- "Unemployment Insurance and Voluntary Unemployment," Report to the National Commission on Unemployment Compensation, October 1979.

Mattila, J. Peter. "Job Quitting and Frictional Unemployment," American Economic Review, March 1974, 64(1), pp. 235-239. 
Medoff, James. "Layoffs and Alternatives Under Trade Unionism," American Economic Review, June 1979, 69(3), pp. 380-395.

Moffitt, Robert and Nicholson, Walter. "The Effect of Unemployment Insurance on Unemployment: The Case of Federal Supplemental Benefits," mimeo, September 1979.

Munts, Raymond. "Partial Benefit Schedules in Unemployment Insurance: Their Effect on Work Incentive," Journal of Human Resources, Spring $1970,5(2)$, pp. 160-176.

Murray, Merrill, G. Proposed Federal Unemployment Insurance Amendments. The W. E. Upjohn Institute for Employment Research, February 1966.

Newton, Floyd C., and Rosen, Harvey. "Unemployment Insurance, Income Taxation, and Duration of Unemployment: Evidence from Georgia," Southern Economic Journal, January 1979, 45(3), pp. 773-784.

Nickell, Stephen. "Estimating the Probability of Leaving Unemployment," Econometrica, September 1979, 47(5), pp. 1249-1266.

Parsons, Donald O. "Models of Labor Market Turnover: A Theoretical and Empirical Survey," in Ronald Ehrenberg (ed.), Research in Labor Economics, Volume 1, 1977, pp. 185-223.

Pencaval, John. An Analysis of the Quit Rate in American Manufacturing Industry. Princeton: Princeton University Press, 1970.

Perry, George. "Unemployment Flows in the U.S. Labor Market," Brookings Papers on Economic Activity, 2, 1972, pp. 245-278.

Salant, Stephen, "Search Theory and Duration Data: A Theory of Sorts," Quarterly Journal of Economics, February 1977, 91(1), pp. 45-63.

Shavell, Steven, and Weiss, Laurence. "The Optimal Payment of Unemployment Insurance Benefits Over Time," Journal of Political Economy, December 1979, 87(6), pp. 1347-1362.

Solon, Gary. "Labor Supply Effects of Extended Unemployment Benefits," Journal of Human Resources, Spring 1979, 14(2), pp. 247-255.

Stafford, Frank P. "More on Unemployment Insurance as Insurance," Industrial and Labor Relations Review, July 1977, 30(4), pp. 521-526.

Topel, Robert, and Welch, Finis. "Unemployment Insurance: What the Theory Predicts and What the Numbers (May) Show, Survey and Extensions," mimeo, UCLA, September 1979. 
Von Furstenberg, George M. "Stabilization Characteristics of unemployment Insurance." Industrial and Labor Relations Review, April 1976, 29(3), pp. 363-376.

Welch, Finis. "What Have We Learned from Empirical Studies of Unemployment Insurance?" Industrial and Labor Relations Review, July 1977, $30(4)$, pp. 451-461. 